\title{
A Study of Parallels between Antarctica South Pole Traverse Equipment and Lunar/Mars Surface Systems
}

\author{
Robert P. Mueller ${ }^{1}$, Stephen J. Hoffman ${ }^{2}$, Paul Thur ${ }^{3}$ \\ ${ }^{1}$ Surface Systems Office, National Aeronautics \& Space Administration (NASA), Mailcode: \\ NE-S, Kennedy Space Center, FL 32899, USA PH (321) 867-2557; Email: \\ Rob.Mueller@nasa.gov \\ 2 Science Applications International Corporation, 2450 NASA Parkway, Houston, Texas \\ 77.058; PH 281.483.9264; email: stephen.j.hoffman@saic.com \\ ${ }^{3}$ Raytheon Polar Services Company (RPSC), 7400 S. Tucson Way, Centennial, CO 80112, USA Ph \\ (800) 688-8606 x32419, (720) 568-2419; Email: Paul.Thur.contractor@usap.gov
}

\begin{abstract}
The parallels between an actual Antarctica South Pole re-supply traverse conducted by the National Science Foundation (NSF) Office of Polar Programs in 2009 have been studied with respect to the latest mission architecture concepts being generated by the United States National Aeronautics and Space Administration (NASA) for lunar and Mars surface systems scenarios. The challenges faced by both endeavors are similar since they must both deliver equipment and supplies to support operations in an extreme environment with little margin for error in order to be successful. By carefully and closely monitoring the manifesting and operational support equipment lists which will enable this South Pole traverse, functional areas have been identified. The equipment required to support these functions will be listed with relevant properties such as mass, volume, spare parts and maintenance schedules. This equipment will be compared to space systems currently in use and projected to be required to support equivalent and parallel functions in Lunar and Mars missions in order to provide a level of realistic benchmarking.

Space operations have historically required significant amounts of support equipment and tools to operate and maintain the space systems that are the primary focus of the mission. By gaining insight and expertise in Antarctic South Pole traverses, space missions can use the experience gained over the last half century of Antarctic operations in order to design for operations, maintenance, dual use, robustness and safety which will result in a more cost effective, user friendly, and lower risk surface system on the Moon and Mars.

It is anticipated that the U.S Antarctic Program (USAP) will also realize benefits for this interaction with NASA in at least two areas: an understanding of how NASA plans and carries out its missions and possible improved efficiency through factors such as weight savings, alternative technologies, or modifications in training and operations.
\end{abstract}




\section{INTRODUCTION}

The Lunar Surface Systems (LSS) Project Office was established within the NASA Constellation Program (CxP) Office in 2007 to "develop a sustained human presence on the moon to promote exploration, science, commerce, and the United States' preeminence in space, and to serve as a stepping stone to future exploration of Mars and other destinations" (Culbert, 2009). The LSS Project Office supports efforts to define a viable Lunar Architecture that will allow humans to return to the moon, and helps define the technology needs and priorities jointly with NASA's Exploration Technology Development Program.

Several Scenarios have been developed to explore the trade space and key parameters of lunar exploration architectures. One such scenario for a Lunar Outpost that the Constellation Program Office found both technically feasible and consistent with the currently base-lined Ares, Orion and Altair transportation system provides:

1) Habitation systems supporting a crew of 4 for 180 days on the lunar surface

2) An ability to produce In-Situ Resource Utilization (ISRU) based oxygen at a rate of 1 metric ton per year and expanded later to 10 metric tons per year

3) Pressurized roving systems to travel hundreds of kilometers from the Outpost

4) Power $->35 \mathrm{~kW}$ of net power production/storage for crewed eclipse periods

5) Surface based laboratory systems and instruments to meet science objectives

6) Sufficient functional redundancy to ensure safety and mission success.

Certain parallels exist between lunar operations scenarios and Antarctic re-supply missions to the Earth's South Pole including the need that both have for environmentally controlled roving systems executing traverses of up to hundreds, or even thousands of kilometers from an outpost or base location. In addition planning activities must occur well ahead of the actual missions so that the correct items are efficiently and adequately packaged and transported to the moon and South Pole in order to sustain human life at these locations.

Another parallel that exists between Antarctic exploration and lunar exploration is the presence of scientists, engineers and support personnel from a variety of international organizations. Lessons learned from international collaboration in Antarctica as well as aspects to be avoided can contribute to a future framework for international operations on the Moon. NASA is currently participating in the International Space Exploration Coordination Group (ISECG) and some of the most active groups are the Interface Standards Working Group (ISWG) as well as the International Architectures Working Group (IAWG) (Laurini, 2009). Common standards, such as using the metric system for all equipment, and standardized interfaces, such as quick disconnect mechanisms, would facilitate international collaboration and possibly add to robustness, redundancy, safety and mission success as spare parts could be jointly qualified for use and interchanged in the field or in space.

A third parallel is the goal of sustainability and In-Situ Resource Utilization (ISRU). By "living off the land" many Arctic and Antarctic expeditions have managed to face seemingly impossible odds of survival and have succeeded and in some cases thrived (Stuster, 1996). Indigenous populations and several case studies including Earnest Shackleton's famous 
journey, where no crew members were lost in the face of extreme adversity, can attest to the value of ISRU. Design and operations for sustainability will teach us how to operate at maximum efficiency while these technologies and practices can be tested in analog field test environments such as Antarctica. In addition waste products can be minimized, re-cycled or eliminated completely.

Furthermore, valuable science activities are conducted in Antarctica on a daily basis which contributes to our understanding of the Earth and its solar system. Ultimately this knowledge will benefit the inhabitants of the Earth and lead to better ways of dealing with our environment (e.g. climate change) and precious resources. On the moon, science will also lead to a better understanding of the Earth and its solar system through the pristine records that exist in the lunar regolith. The challenge is to find a way that science activities can be integrated seamlessly into daily exploration activities such as traverses for logistics re-supply.

Finally power and energy self sufficiency is a topic of great interest to all explorers and the well being of the earth's population in general. History has shown that energy rich exploration is advantageous and communities can prosper when energy is available at a reasonable cost. Currently large quantities of diesel fuel are transported in convoys across 1,600 kilometers in each direction in order to re-supply remote outposts such as the South Pole station. Energy self sufficiency and storage methods through the use of advanced technologies such as solar power, fuel cells, wind turbines, thermal gradients, advanced chemical storage batteries, flywheels, fission power and beyond would dramatically reduce the mass and volume of re-supply convoys. In addition technologies destined for the Moon, Mars and Asteroids could be field tested in a hostile thermal environment with multiple operational cycles, data acquisition, remote communications and shared costs.

In response to the NASA - USAP Antarctic Traverse Workshop held in Houston in August 2009 (Hoffman, 2009), a dialogue has been initiated to explore long term collaboration on Traverse logistics and planning, which should benefit both organizations. NASA may benefit through a detailed analysis of support equipment required to supply and execute traverses in the Antarctic over the last 50 years. The USAP may benefit from any logistics planning tools or new technologies that may be available through NASA engineers. This is seen as the first step in the development of a close working relationship in the years to come.

\section{ANTARCTIC TRAVERSE OPERATIONS OBSERVATIONS}

The Traverse Operations Department, of Raytheon Polar Services Company (RPSC), is in the process of standardizing the operations of all traverses in the Antarctic in support of the US Antarctic Program (USAP). Currently, the USAP traverses from McMurdo Station to: Black Island, Marble Point, Windless Bight, various other locations in McMurdo Sound, and to the South Pole. The vision is to have one standard for all traverses that the USAP undertakes so as to ensure consistency in communications, emergency preparedness, contingency planning, personnel recruitment, daily operations, crevasse detection and avoidance, inventory planning, and technological development. 
The main tasking for Traverse Operations can be broken into two general categories;

(a) document creation and

(b) technological developments / operational modifications.

Some of the documents that will be required are:

a) library of standard operating procedures (SOPs),

b) master inventory list of available equipment,

c) inventory list of minimum required support equipment,

d) maintenance history library for all support equipment,

e) standard pre-traverse and field maintenance schedule for all support equipment,

f) load planning tool (CRREL developed load planner based on mobility research) and

g) detailed annual operational data.

Some of the technological developments / operational modifications should include:

a) refining and minimizing supplies taken into the field,

b) improvements to the high molecular weight (HMW) polyethylene sleds,

c) advancements in crevasse detection / assessment equipment,

d) modifications to improve the durability of fuel bladders and containment envelopes,

e) development of a cushioning interface between HMW sleds and hauled cargo,

f) reduction to tare weights of traverse sleds (structural plastics instead of steel),

g) autonomous tractor development (reduces the number of operators required per 12 hour shift and could allow for 24 hour operations),

h) incorporation of alternative energy systems into traverse platforms,

i) reduced waste production (specifically waste water),

j) expansion of route assessment tools (remote sensing / airborne radar / autonomous radar vehicle), and the

k) securing of a heated work space to inspect and prepare critical traverse equipment.

The USAP is at a critical point in the pre-planning stages of traverses to several other Antarctic locations that will cover thousands of kilometers (See Figure 1). Two sites in West Antarctica that will be accessed overland in the coming years will be Pine Island Glacier and WAIS Divide camp. Other destinations, in East Antarctica, that will be accessed from the current South Pole route will be AGAP South and the WISSARD drilling sites. These traverses will require years of pre-planning and must take advantage of as many technological developments as possible.

The optimum maintenance schedule for all vehicles and generators was identified prior to procurement of the equipment. All equipment was designed so that the service interval would be as long as possible. Most equipment has service intervals long enough to allow for one full round trip before service is required. This greatly reduces the probability of having to perform maintenance activities while in the field, as well as reduces the amount of service parts and fluid required to be carried. 


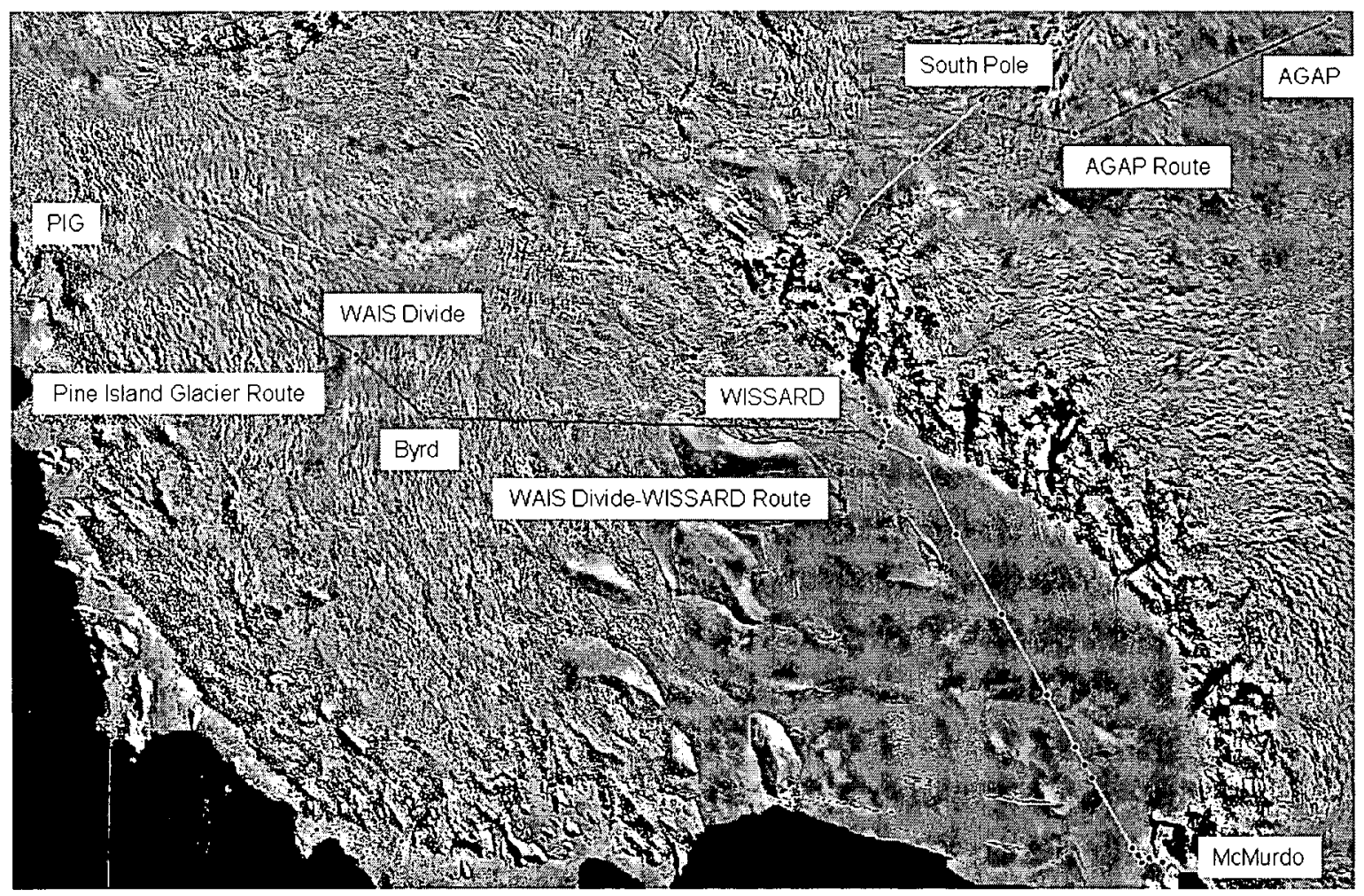

Figure 1. Map of current South Pole Traverse Route (green) and Proposed Routes for Traverses within the next 4 years (red).

Currently, most USAP traverse technological developments / operational modifications are gained through a NSF funded, direct collaboration with Cold Regions Research and Engineering Laboratory (CRREL) engineers. There is a continuous cycle of field testing, assessment, and development. Inviting NASA engineers into the development cycle should prove to be beneficial to the USAP in the long term.

Traverse Operations has already realized a benefit from the initial interaction with NASA engineers in two ways:

a) In completing the initial assessment of how the USAP conducts its traverses, we have identified the need for improved record keeping, specifically inventory databases.

b) The creation of the support equipment spreadsheet has generated an interest in better maintaining this list of field equipment and scrutinizing it for missing, redundant, or overstocked items.

The creation of any new department, in any organization, requires great effort and planning. It is a fortunate circumstance that NASA has approached the USAP to request collaboration on the logistics of planning traverses. This combined effort has increased the tempo in the 
process of examining current documents, creating inventory spreadsheets and identifying missing information / data.

Generating a list of every piece of equipment that is carried on the traverse creates a realization of just how many items are required to support an overland traverse traveling several thousand miles across the Antarctic over the course of an austral summer (more than 550 line items have been identified on the list up to this point). Because the traverse is in its beginning stages, there has not been an emphasis placed on reducing inventories to minimum levels, or in completing comprehensive post traverse inventory counts to date. As the traverse becomes more efficient in all operational areas and due to the extremely long and complicated logistics chain for all items in McMurdo, there will be an emphasis placed on using a minimum amount of inventory to support the traverse. The overall weight of individual traverse inventory items is not as critical as the amount of space required for storage of those items. In general, the support sleds are not at maximum weight, they are "cubed out" (sleds could accept more weight, but there is no available space). Better inventory tracking is one way to reduce the quantity of support items. Finding alternative tools is beneficial as well. For example, if the traverse is able to switch from a gasoline powered heater to an electrical heater, there will be a two-fold benefit. The electric heaters are easier to maintain, with fewer parts, and there would be no reason to stock barrels of gasoline. Procuring a larger capacity welder / generator will allow the traverse to remove the small back-up generator and the wirefeed welder from its inventory.

Almost 95\% of the payload delivered to the South Pole is fuel. Any improvement that increases the overall fuel efficiency of the traverse directly results in a larger payload delivered to South Pole. Currently, each pound of cargo delivered requires about 1.25 pounds of support equipment (see Table 1). Due to the extremely small total weight of the majority of individual inventory items, it is not foreseen that this ratio could be significantly improved until a major development is made in reducing the weight of the largest parts of the support equipment (e.g. - support sled bases). Removing the steel skis under each building should allow this ratio to approach 1:1. This reduction in traverse total weight combined with lower sled resistance may improve the ratio even further.

Table 1: A summary table of traverse weights broken into various categories.

\begin{tabular}{|r|r|}
\hline \multicolumn{1}{|c|}{ Item } & Total Weight (lbs) \\
\hline Support equipment & $324,207.0$ \\
\hline Tools & $15,076.5$ \\
\hline Miscellaneous inventory & $5,678.1$ \\
\hline Spare parts & $6,484.3$ \\
\hline Medical equipment & 280.0 \\
\hline Sleds & $295,690.0$ \\
\hline Tractors & $409,400.0$ \\
\hline Total weight of traverse equipment & $\mathbf{1 , 0 5 6 , 8 1 5 . 9}$ \\
\hline Total weight of cargo delivered & $\mathbf{8 4 7 , 5 4 5 . 0}$ \\
\hline
\end{tabular}


Employing a mixture of old and new technologies limits the total amount carried forward by the traverse (See Figures $2-6$ ). The amount of cargo hauled by each delivery tractor, on new sled technology (HMW), is significantly more than the amount hauled by the support tractors on old sled technology (steel). In general, four tractors are currently used to carry all support items forward; this includes living quarters, food, supplies, parts and tools, as well as fuel required for the traverse. This leaves four tractors that are dedicated to hauling delivery cargo. This is a 1:1 ratio of support tractors to delivery tractors. In the current configuration (See Table 2), tractors 1, 2 and 3 are hauling $\sim 100,000 \mathrm{lbs}$ of steel skis and framework. It is estimated that, if the traverse could use newer technology to reduce the tare weight and resistance of the support sleds, that the traverse could possibly add another 15,000 gallons of delivery fuel to create an optimum configuration (Ref. Table 3). Basically this would move the ratio of support tractors to delivery tractors from $1: 1$ to $3: 5$.

This demonstrates how critical it is to incorporate new technology into the support sleds to increase the overall efficiency of the traverse. Sleds with lower resistance should provide better fuel economy, as well as increase the amount of fuel hauled (increases the fuel delivered to burned ratio).

Table 2: Configuration on departure in November 2009.

\section{Support tractors}

Tractor 1- Living \& Power Modules

$135,000 \mathrm{lbs}$

Tractor 2- Tool Shed, 4,000 gal support fuel, delivery cargo \& small berthing unit

$125,000 \mathrm{lbs}$

Tractor 3- Reefer unit \& 18,000 gal support fuel

Tractor 4- 24,000 gal support fuel

$171,000 \mathrm{lbs}$

Delivery tractors

Tractor 5-30,000 gal delivery fuel

$176,000 \mathrm{lbs}$

Tractor 6-30,000 gal delivery fuel

$220,000 \mathrm{lbs}^{*}$

Tractor 7-30,000 gal delivery fuel

$220,000 \mathrm{lbs}^{*}$

Tractor 8-24,000 gal delivery fuel

$\sim \mathbf{1 1 4 , 0 0 0}$ gallons delivered / $\sim \mathbf{4 6 , 0 0 0}$ gallons burned $=\quad \mathbf{2 . 4 8}$ gal delivered: 1 gal burned

*All tractors do not have equal pulling power that is why Tractors 5, 6, and 7 have higher payloads.

Table 3: Potential configuration if support sled base tare weights could be reduced.

\section{Support tractors}

Tractor 1- Living \& Power Modules, 9,000 gallons support fuel

Tractor 2- Reefer Unit, Tool Shed, 4,000 gal support fuel, small berthing unit

Tractor 3-30,000 gal support fuel

$220,000 \mathrm{lbs}^{*}$

$176,000 \mathrm{lbs}$

\section{Delivery tractors}

Tractor 4-24,000 gal delivery fuel

Tractor 5-24,000 gal delivery fuel

Tractor 6-30,000 gal delivery fuel

Tractor 7-30,000 gal delivery fuel

Tractor 8-24,000 gal delivery fuel

$\sim 132,000$ gallons delivered $/ \sim 43,000$ gallons burned $=\quad 3.07$ gal delivered: 1 gal burned

$\wedge$ These weights are estimated since it is unknown what an HMW support sled would look like.

* All tractors do not have equal pulling power that is why certain tractors have higher payloads. 
Currently, the South Pole traverse does not regularly assess the snow conditions (strength or density) along the 1,030 mile route. Since the traverse is constantly travelling over the same trail, it is assumed that the snow conditions will remain the same from year to year. In addition to the use of the CRREL load planning tool, obtaining surface measurements of snow conditions along the proposed routes to WISSARD, PIG, AGAP and WAIS Divide will assist in the proper planning of the loads to be carried by each tractor on those traverses.

The traverse indirectly supports Science in the Antarctic. It acts as a logistics tool by removing the requirement for some science equipment, or fuel, to be flown into the field. It is anticipated that at some point in the future, Science may be accomplished along the trail, in conjunction with a logistics type traverse.

Incremental improvements to crevasse assessment tools, the CRREL load planning tool, HMW sleds, bladders, and containment wrappers have been successful, but we should continue to work with the manufacturers, CRREL engineers, and possibly NASA engineers, to make further improvements.

Areas that require the use of new technologies and engineering consultations are:

a) incorporation of alternative energy,

b) reduction of waste water production,

c) use of lighter weight structural materials,

d) development of autonomous vehicles and / or route assessment tools, and an $\mathrm{HMW} /$ cargo cushioning interface.

In order for Traverse Operations to be successful and to lead the way in evolving Antarctic traversing, a continuous flow of information between traverse management and engineers is required.

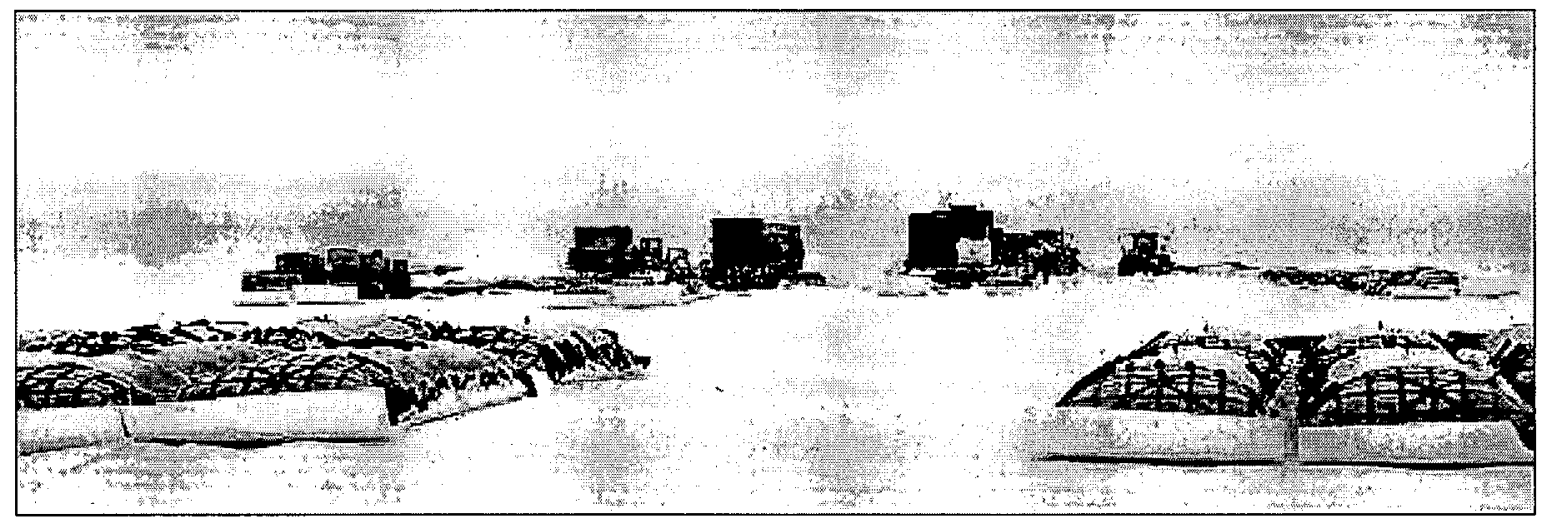

Figure 2. Foreground, new technology, HMW sleds with 3,000 gallon fuel bladders secured on them. Camped for the night on the Ross Ice Shelf, Antarctica. Photo by Paul Thur. 


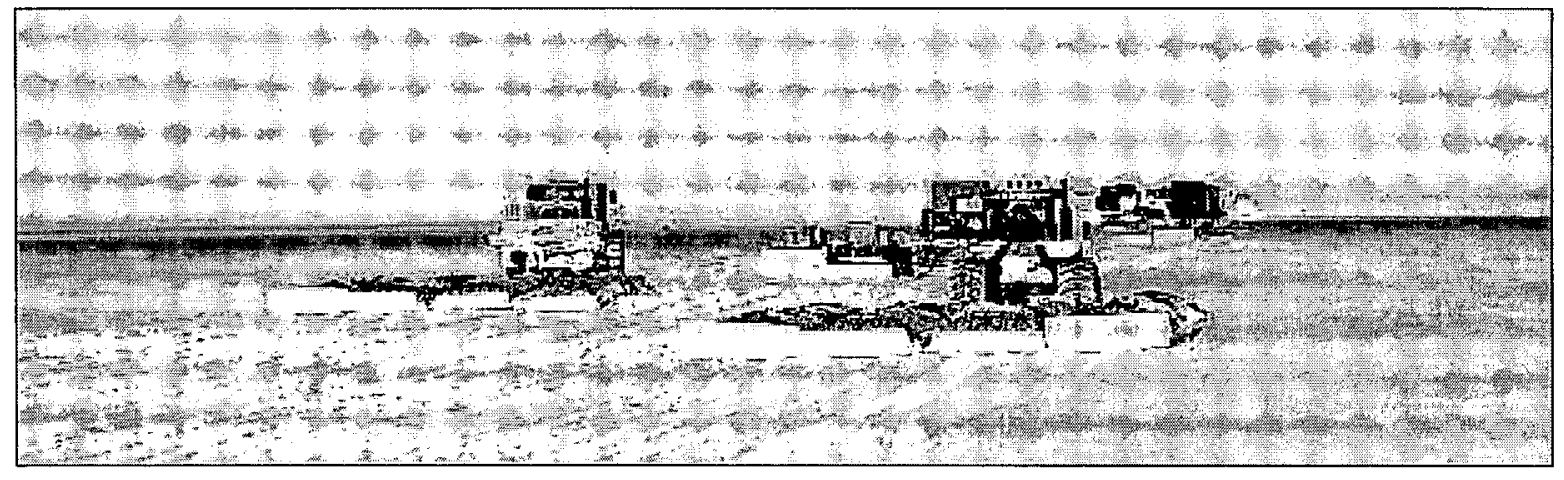

Figure 3. Foreground, new technology, HMW sleds with 3,000 gallon fuel bladders secured on them. Moving down the trail on the Ross Ice Shelf, Antarctica. Photo by Paul Thur.

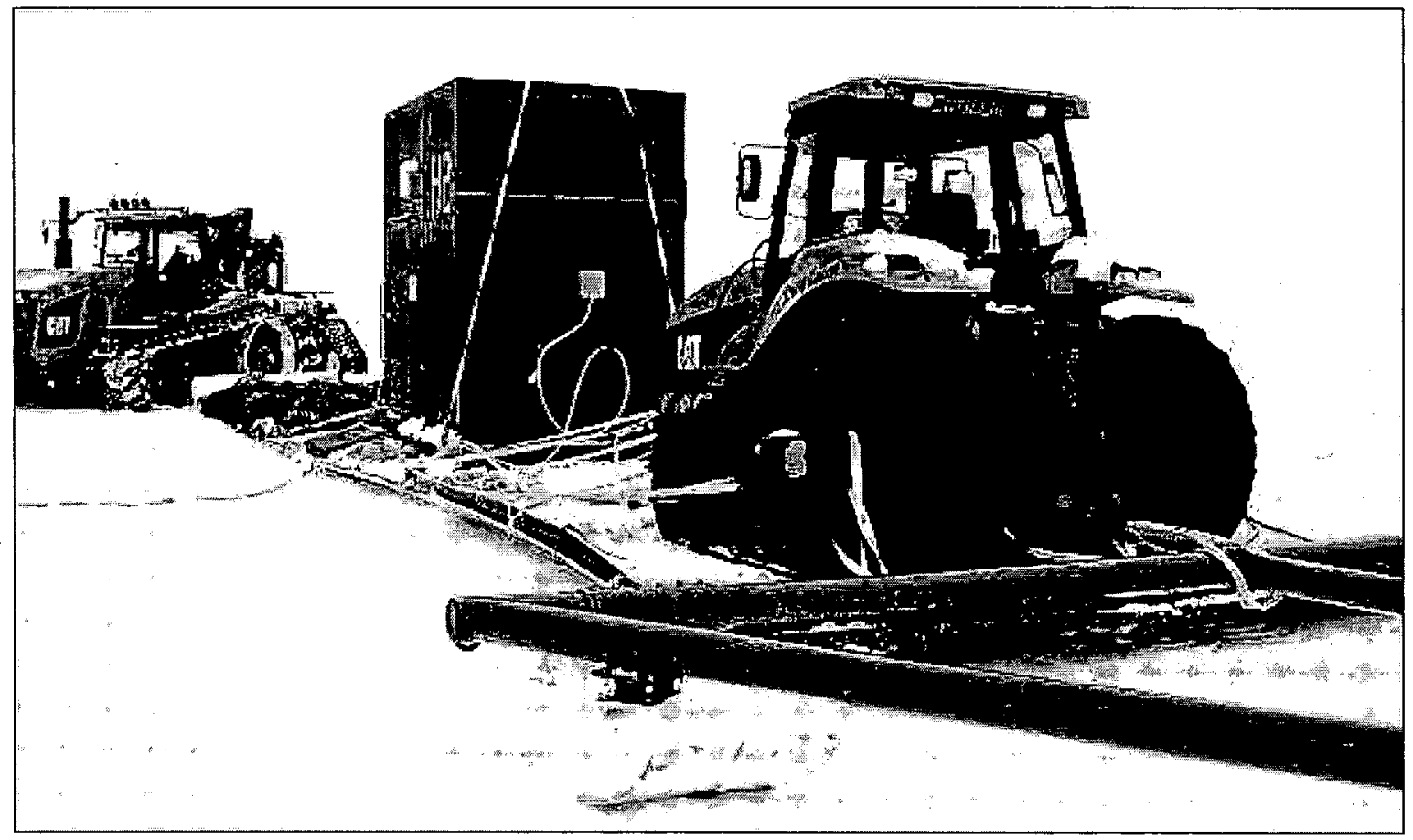

Figure 4. New technology, HMW sleds with cargo and a remote berthing unit secured on top. Camped along the trail, near the South Pole, Antarctica. Photo by Paul Thur. 


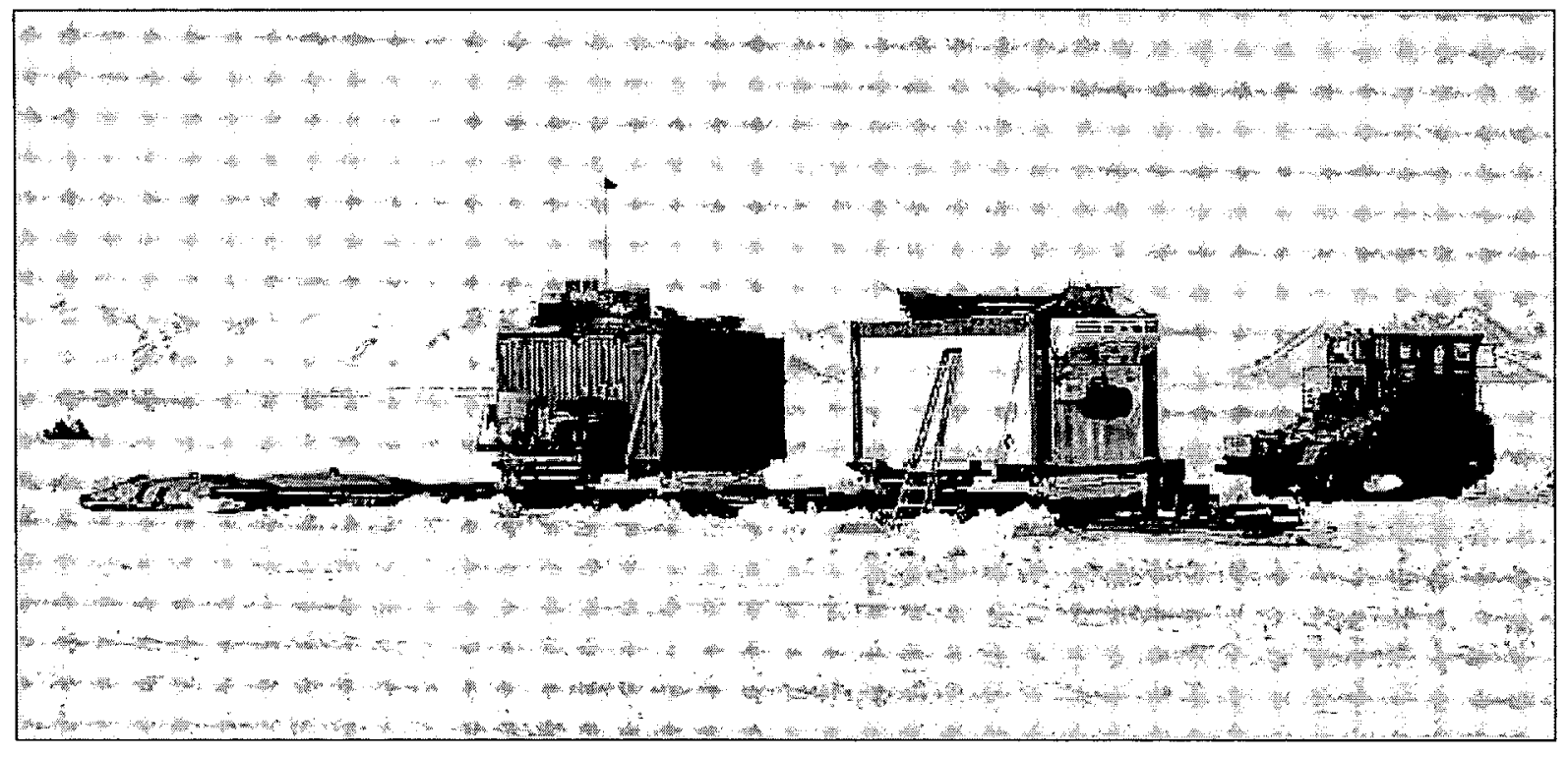

Figure 5. Old technology, support sleds with steel skis and frames. Tool Shed, left side, Reefer Unit, right side. On the Ross Ice Shelf near the Trans-Antarctic Mountains, Antarctica. Photo by Paul Thur.

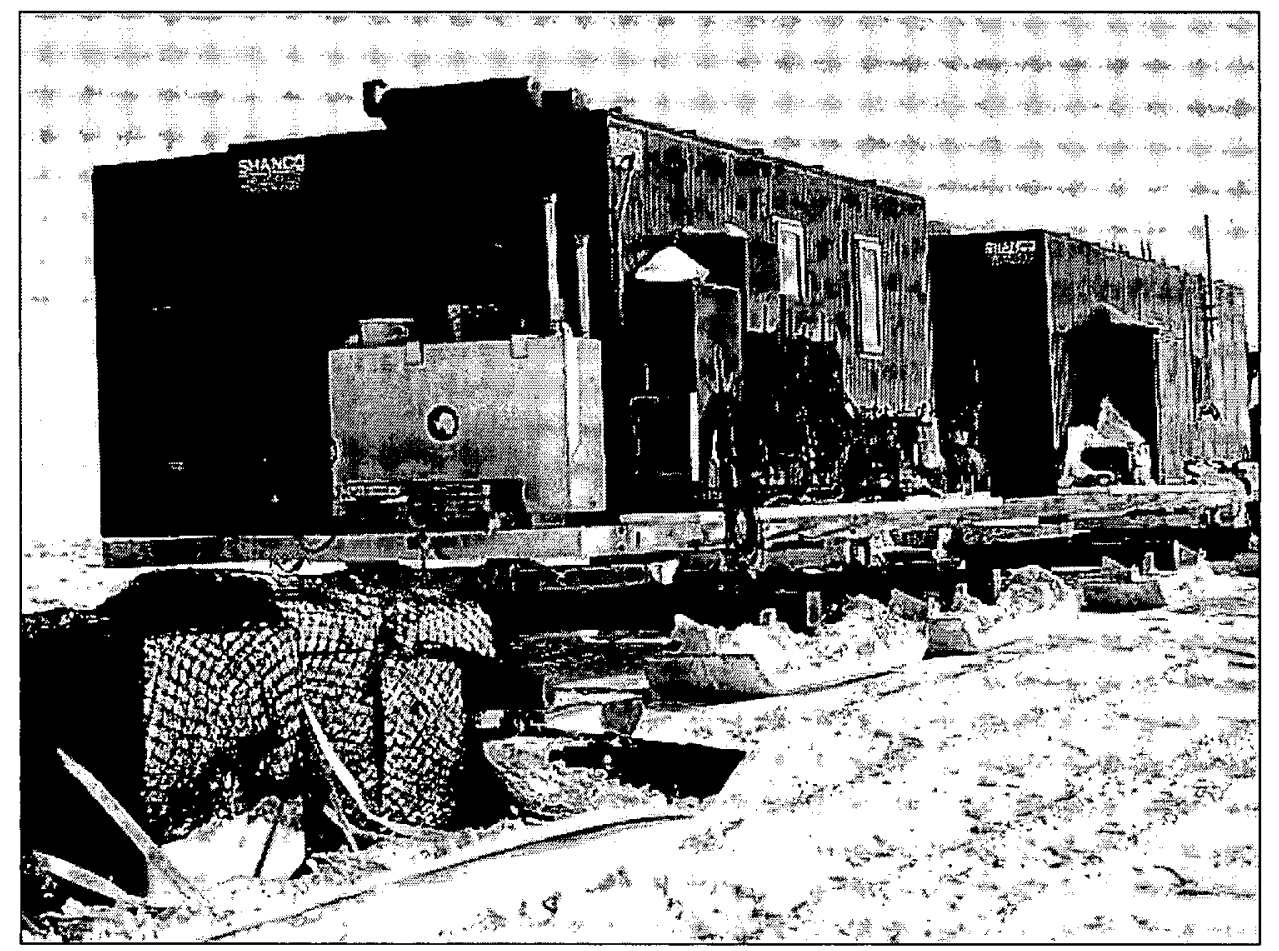

Figure 6. Old technology, support sleds with steel skis and frames. Generator Module, left side, Living Module, right side. On the Leverett Glacier in the Trans-Antarctic Mountains, Antarctica. Photo by Bay Baskin. 


\section{LUNAR SURFACE SCENARIO PRELIMINARY ASSESSMENT}

The NASA CxP LSS office has been actively engaged in a trade study of various scenarios which is aimed at flushing out the critical variables and issues in a lunar architecture that will meet NASA and international collaborators objectives and goals. Since there are a variety of different scenarios, then it is necessary to pick one scenario in order to provide some basis of comparison to Antarctic expeditions and anticipated human Mars missions. The scenarios being studied by the LSS office are listed in Table 4. Previous NASA studies have include the Exploration Systems Architecture Studies (ESAS) in 2005 and Lunar Architecture Team (LAT I\&II) studies in 2006-2008. Current thinking has evolved and a variety of lunar surface systems elements are being proposed for the current CxP LSS architecture studies. These elements include mobility assets which can be used to traverse to points of interest over a range of hundreds of kilometers in pressurized and un-pressurized versions. The logistics and cargo necessary to carry out these traverses include the Earth to space transportation and time phasing or manifesting of these elements and related support equipment. NASA LSS Scenario 4 has been chosen as the basis for comparison in this paper. This scenario emphasizes architecture robustness for many possible futures. The NASA Lunar Concept Capability Review (LCCR) was held in June 2008 and demonstrated a concept for a Lunar Outpost that was both technically feasible and consistent with the transportation system. (Culbert, 2009).

Table 4. NASA Lunar Surface Systems Office Scenarios currently being studied.

\begin{tabular}{|c|l|}
\hline Scenario & \multicolumn{1}{|c|}{ Description } \\
\hline 1 & Full Outpost Assembly from LCCR (Trade Set 1) \\
\hline 2 & Mobility oriented Outpost from LCCR (Trade Set 2) \\
\hline 3 & Habitation oriented Outpost from LCCR (Trade Set 3) \\
\hline 4 & $\begin{array}{l}\text { Rebuild of LCCR scenarios increasing crew flights to at least 2 per } \\
\text { year }\end{array}$ \\
\hline 5 & $\begin{array}{l}\text { Nuclear power based scenarios - Use a fission reactor as the } \\
\text { primary power source }\end{array}$ \\
\hline 6 & $\begin{array}{l}\text { Power beaming scenarios - Consider ways to beam power from } \\
\text { orbit or surface to systems }\end{array}$ \\
\hline 8 & $\begin{array}{l}\text { Recyclable lander - Scenarios that make massive reuse of lander } \\
\text { components to build up the Outpost and surface infrastructure }\end{array}$ \\
\hline 9 & $\begin{array}{l}\text { Extreme mobility - Scenarios that deploy Small Pressurized Rovers } \\
\text { early and use them as primary habitation }\end{array}$ \\
\hline 10 & $\begin{array}{l}\text { Improving Lander offloading - Scenarios that support a lander } \\
\text { configured to make unloading much less complex }\end{array}$ \\
\hline 11 & $\begin{array}{l}\text { Refuelable lander - Scenarios that support a lander designed for } \\
\text { multiple flights to and from LLO }\end{array}$ \\
\hline Mars Centric - Scenarios that optimize Mars exploration ties \\
\hline
\end{tabular}


The assumed landing sequence of lunar elements is shown in Figure 7. Four crew members will land and deploy surface elements in incrementally longer missions starting with 7 days and extending to 180 day rotations to a lunar outpost.

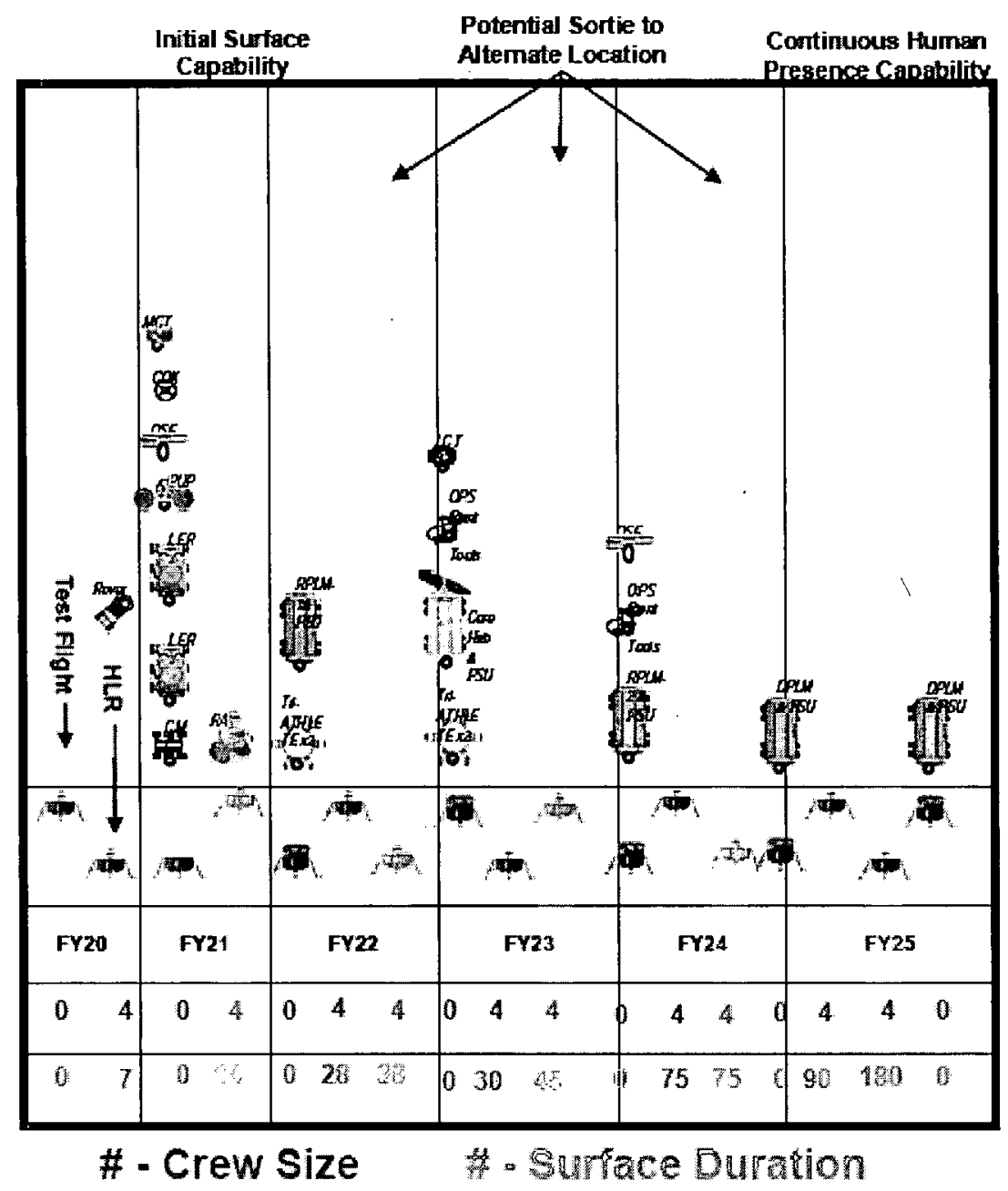

Figure 7. Scenario 4.2.1.20 Manifest showing Various Elements and Phasing

The elements that are included in Scenario 4.2 .1 (Culbert, 2009) are described below and then examined in the context of parallels to an Antarctic Mission. 


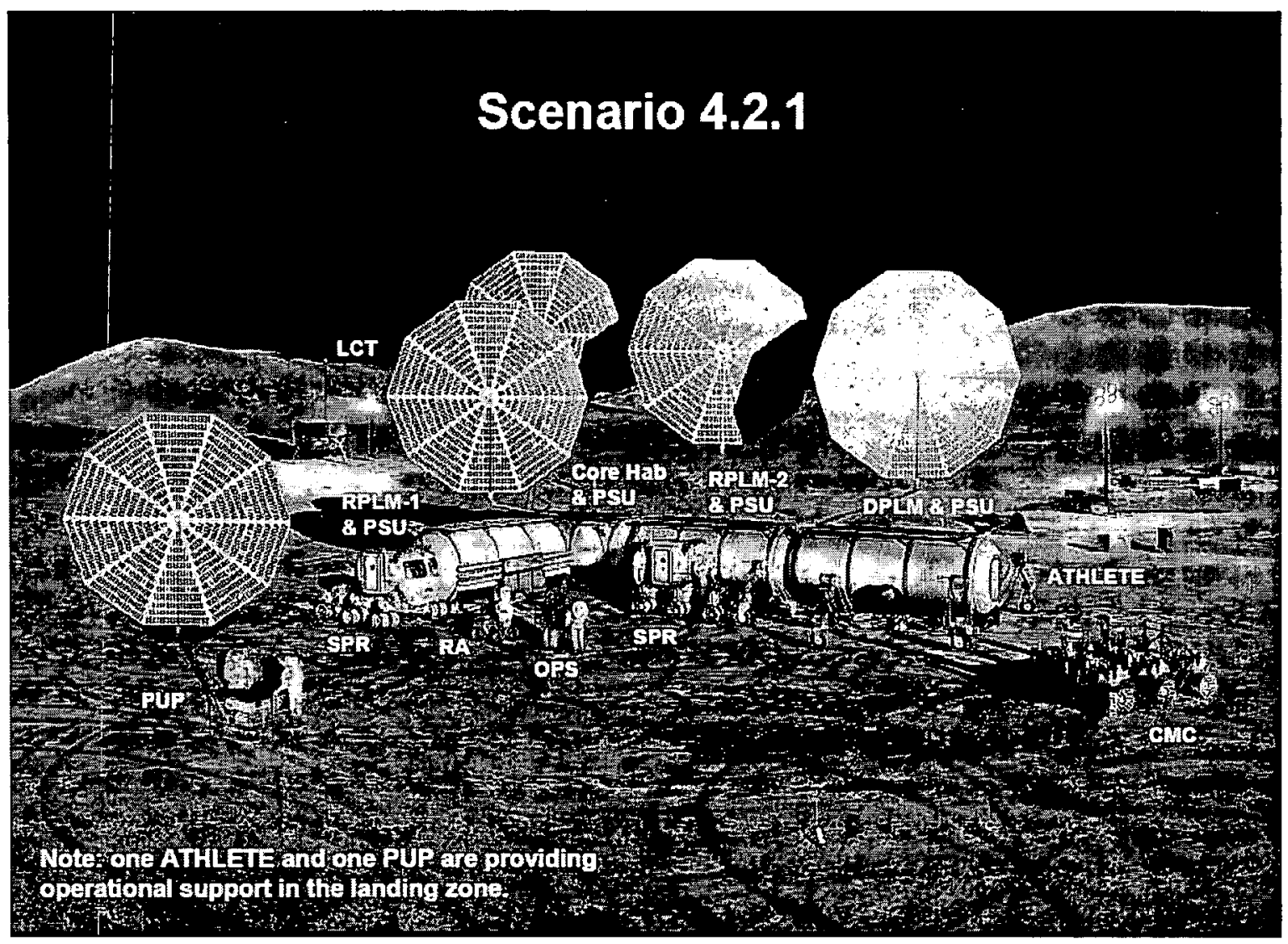

Figure 8. Lunar Outpost NASA LSS Scenario 4.2.1 Elements

$\begin{array}{ll}\text { ACronym } & \text { Name } \\ \text { ATHLETE } & \text { All-Terrain Hex-Legged Extra-Terrestrial Explorer } \\ \text { CDK } & \text { Chassis Driving Kit } \\ \text { CMC } & \text { Crew Mobility Chassis } \\ \text { DPLM } & \text { Disposable Pressurized Logistics Module } \\ \text { LCT } & \text { Lunar Communications Terminal } \\ \text { LER } & \text { Lunar Electric Rover } \\ \text { MCT } & \text { Mobility Chassis Toolkit } \\ \text { OPS } & \text { Oxygen Production System } \\ \text { OSE } & \text { Offloading \& Support Equipment } \\ \text { PSU } & \text { Power \& Support Unit } \\ \text { PUP } & \text { Portable Utility Pallet } \\ \text { RPLM } & \text { Reusable Pressurized Logistics Module } \\ \text { SPR } & \text { Small Pressurized Rover } \\ \text { SSU } & \text { Structural Support Unit }\end{array}$

Function
Surface Mobility
Surface Mobility
Surface Mobility
Logistics \& Supportability
Communications
Surface Mobility
Site prep/science
ISRU
Surface Operations and Unloading
Power and Structural Interface
Power
Habitation. Logistics \& Supportability
Extended Surface Mobility
Structural Interface

Figure 9. Element Acronyms and Functions 


\section{Surface Habitation}

The surface habitat modules support a crew of four for up to 180 days ( 210 days contingency) and are made of Aluminum Lithium alloy ( $3.0 \mathrm{~m}$ diameter $x 8.35 \mathrm{~m}$ length $\sim 55 \mathrm{~m}^{\wedge} 3$ of pressurized volume per module). The total maximum volume is $\sim 242 \mathrm{~m}^{\wedge} 3$. This results in a core habitat mass of 8.7 metric tons ( $\mathrm{mt}$ ) and average operating power $5.9 \mathrm{~kW}$, RPLM mass of $4.3 \mathrm{mt}(1.3 \mathrm{~kW})$ and RPLM-2 mass of $4.9 \mathrm{mt}(2.9 \mathrm{~kW})$. The RPLMs are delivered as part of the logistics re-supply.

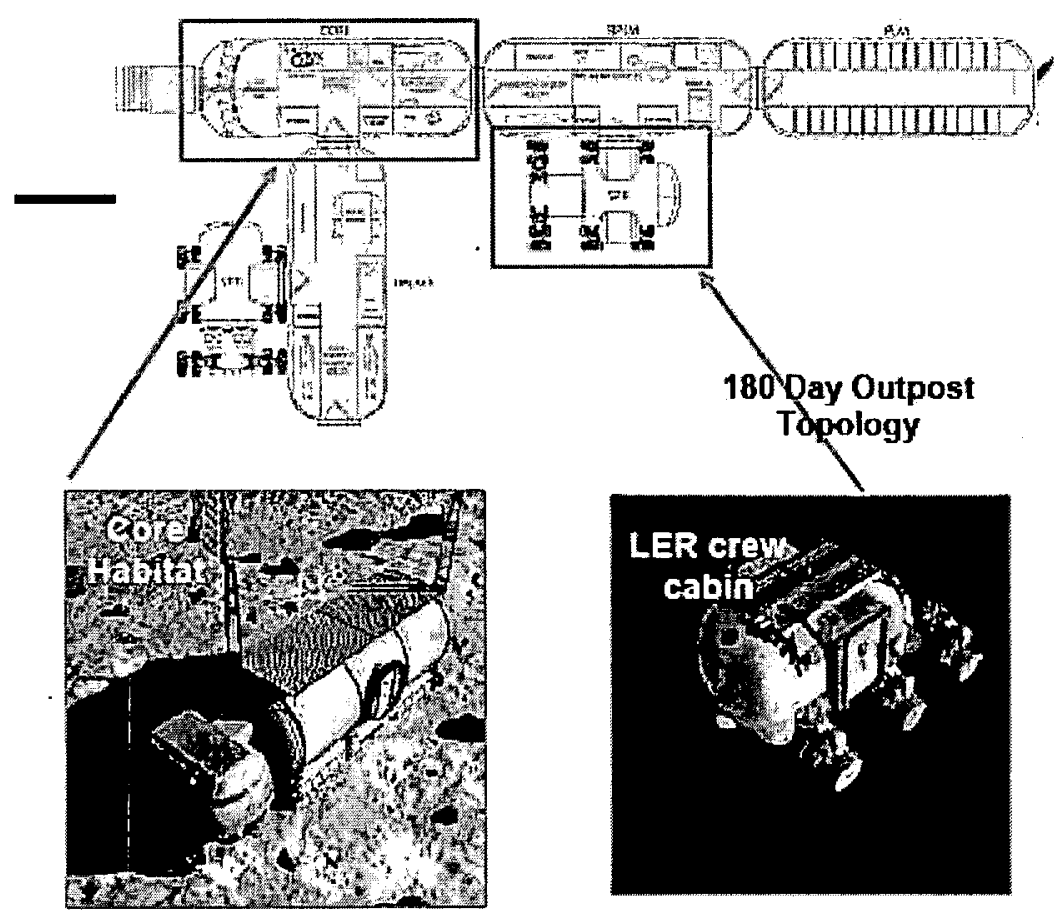

Figure 10. Surface Habitation Concept

\section{Extra-Vehicular Activity (EVA) Suit}

The EVA suit enables crew members to do excursions onto the lunar surface. Additional hardware required beyond the pressure garment are:

a) Portable Life Support System (PLSS)

b) Recharge and Buddy Umbilicals

c) Helmet Camera

d) EVA Visor Assembly

e) EVA System Servicing Equipment

f) General EVA tools

The nominal suit operating pressure is $30 \mathrm{kPA}$ (4.3 psi) and the PLSS is designed for 8 hours of independent operation. Maintenance on the suit is required every 28 Earth days. 


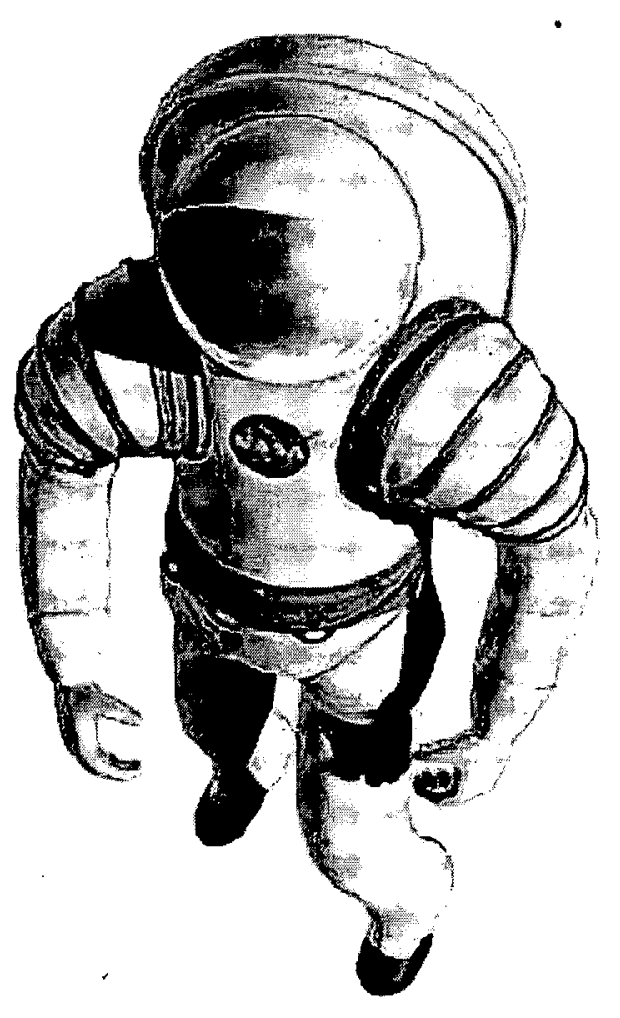

Figure 11. EVA Suit Concept for Lunar Surface Operations by the Crew.

\section{Altair Lander Airlock}

The airlock can support two crew members in order to conduct EVAs on the lunar surface during sortie mission. Ninety percent of the gas is recovered when the airlock is cycled and it allows daily EVAs by the crew. The airlock volume is approximately $5.5 \mathrm{~m}^{\wedge} 3$.

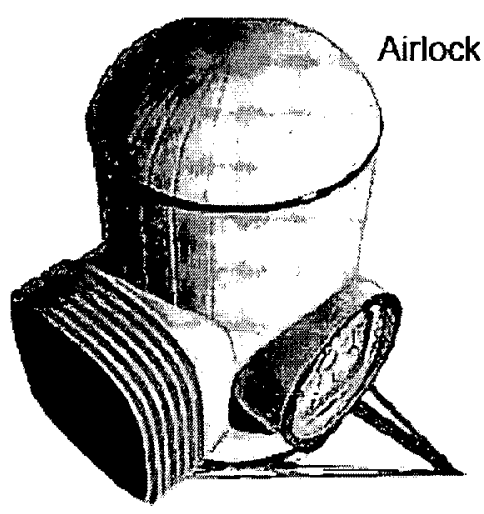

Figure 12. Altair Lander Airlock 


\section{Lunar Electric Rover (LER): A Small Pressurized Rover Concept}

Each LER provides a mobile pressurized environment for a two person crew on extended exploration and scientific operations or for a four-person crew in contingencies. Comfortable shirt-sleeve, sensor augmented environment for gross translations and geological observations reduces time in EVA suit and extends exploration range and productivity. Suitports enable rapid egress to the planetary surface and rapid ingress to the shelter of the rover in emergencies while enabling significant savings in crew time and consumables. Two common hatches provide docking and transfer under pressure with habitat, logistics elements and possibly lander, which may eliminate need for a lander airlock. A fusible heat sink provides thermal management and SPE radiation protection while roving on surface. Using each other as backup, two LERs enable $2 \times 2$-person crews to explore up to $1000 \mathrm{~km}$ from the lander / outpost with additional logistics and power augmentation. (Culbert, 2009)

\section{Specifications:}

- Range $=100 \mathrm{~km}$ ( 3 days), 1,000 km (14 days)

- Mass $=2,952 \mathrm{~kg}$ (excluding chassis)

- Crew $=2$ (4 in contingency)

-LER cabin pressure $\sim 55 \mathrm{kPa}(8 \mathrm{psi})$

- Excursion duration $=3$ days nominal extended to 14 days with Portable Utility Pallet

-EVA driving station enables operation as a UPR

-Environmental shelter protects suits while attached to suitports

-LER recharges PLSS when stowed. LER recharges ECLSS when attached to RPLM.
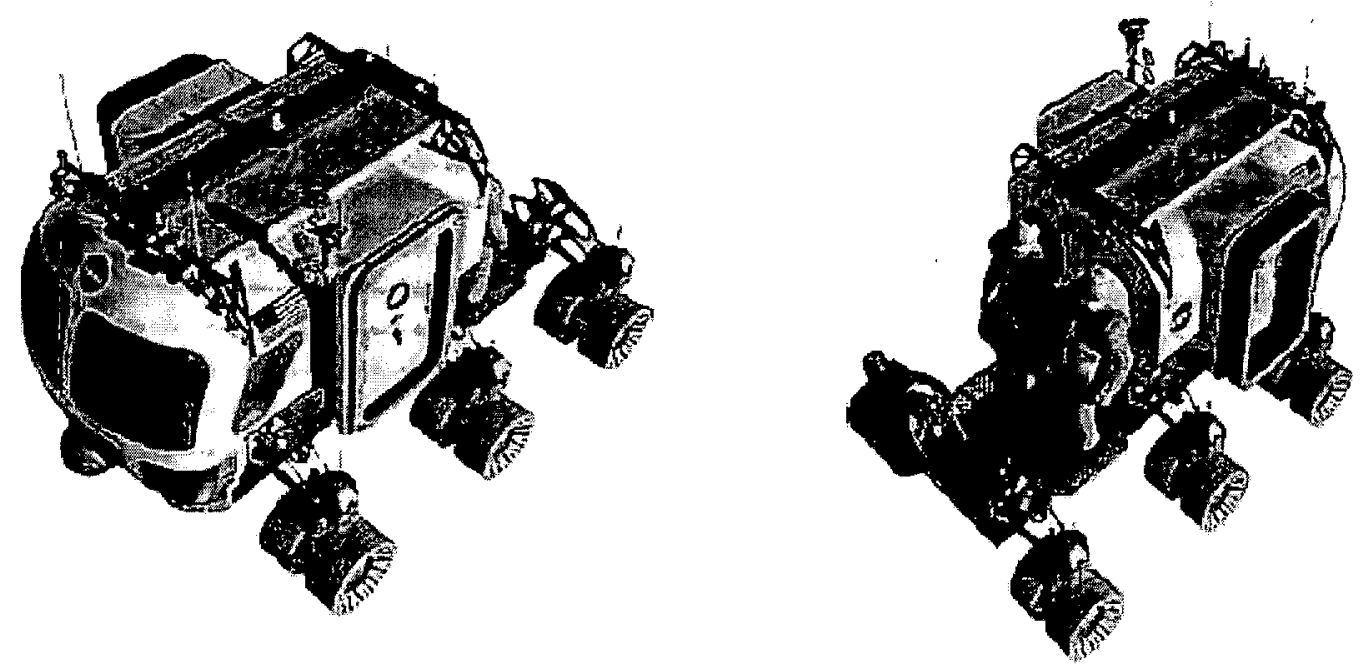

Figure 13. Lunar Electric Rover (LER) Concept for Crew Surface Transportation 


\section{Crew Mobility Chassis (CMC)}

The CMC provides a mobile base for pressurized and unpressurized crew operations for up to four crew, mobile power, ISRU, and site preparation. (Culbert, 2009)
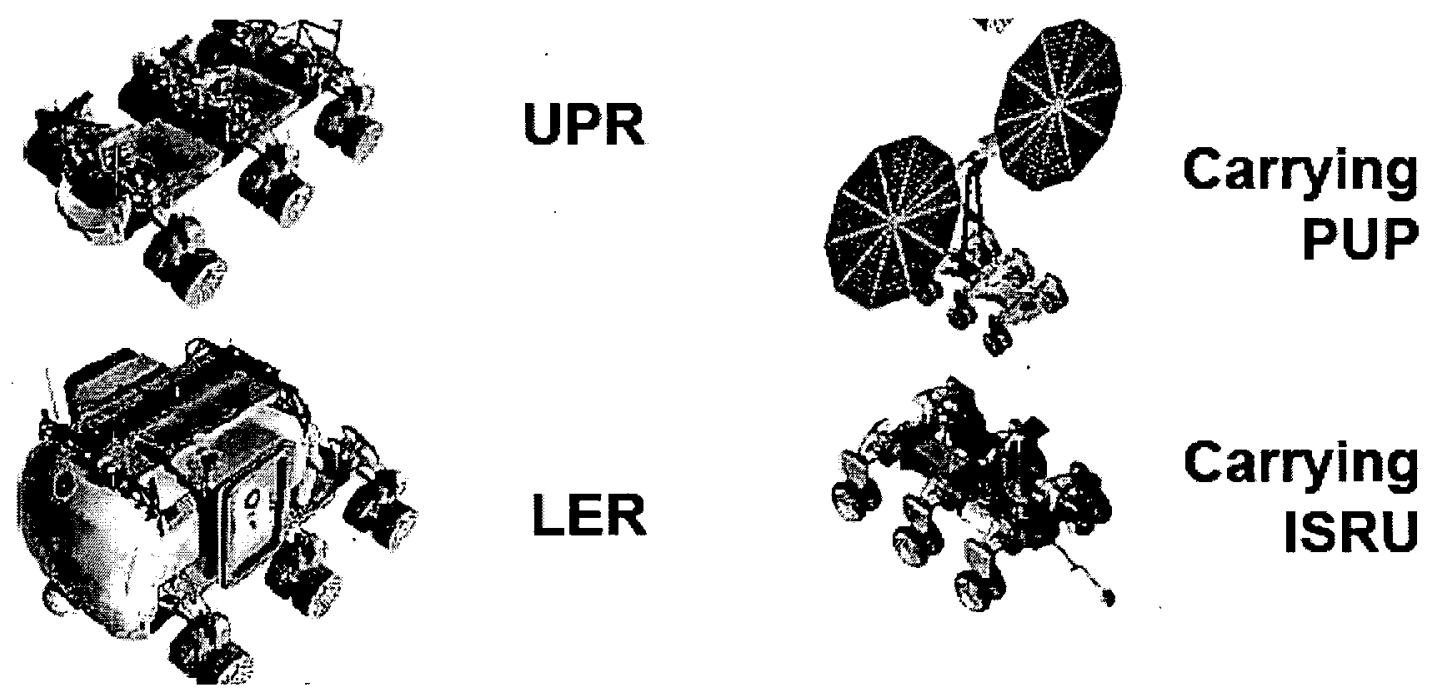

Figure 14. Various Configurations for the Crew Mobility Chassis (CMC).

(UPR $=$ Unpressurized Rover, PUP $=$ Portable Utility Pallet, LER = Lunar Electric Rover, ISRU = In Situ Resource Utilization)

The lunar surface Mobility platform can be re-configure to provide various functional modes of operation in a lunar surface operation, as shown above.

Specifications:

$.969 \mathrm{~kg}$ dry vehicle mass

$\cdot 3,000 \mathrm{~kg}$ payload

$->100 \mathrm{~km}$ range, upgradable with PUPs

$\cdot 0-5 \mathrm{kph}$ low gear, 0-20 kph high gear

$\cdot 30^{\circ}$ slope capability

- "Zero turning radius"crab drive

-Chassis leveling $0.75 \mathrm{~m},+/-10$ degrees

- $20 \mathrm{kWh}$ onboard energy storage (Li-ion battery)

Driven On-board or remotely supervised 


\section{All Terrain Hexapod Legged Extra-Terrestrial Explorer (ATHLETE)}

The ATHLETE consists of two three-legged halves that combine with a PSU or SSU for offloading and long-duration excursions or with each other for operations around the outpost. Wheel-on-limbs design allows payloads to be directly "walked" off of lander deck 6+ $\mathrm{m}$ high at tilts of $12^{\circ}$ or more and over rough terrain with up to $30^{\circ}$ slopes. When carrying a pressurized living space and sufficient power, ATHLETE enables global exploration operations. (Culbert , 2009)

Specifications:

-Mass: $2256 \mathrm{~kg}$ (complete ATHLETE)

-Payload: $14.5 \mathrm{t}$ in three-legged iron cross

- Range is a function of available power

- $10 \mathrm{kph}$ max speed $\cdot$ At least $30^{\circ}$ slope capability•

$6.5 \mathrm{kWh}$ onboard Li-ion battery energy storage providing

$.5 \mathrm{~km}$ travel with max payload before recharge

-225Wh solar array for daylight operations and battery recharge $\cdot$ Driven onboard or remotely supervised
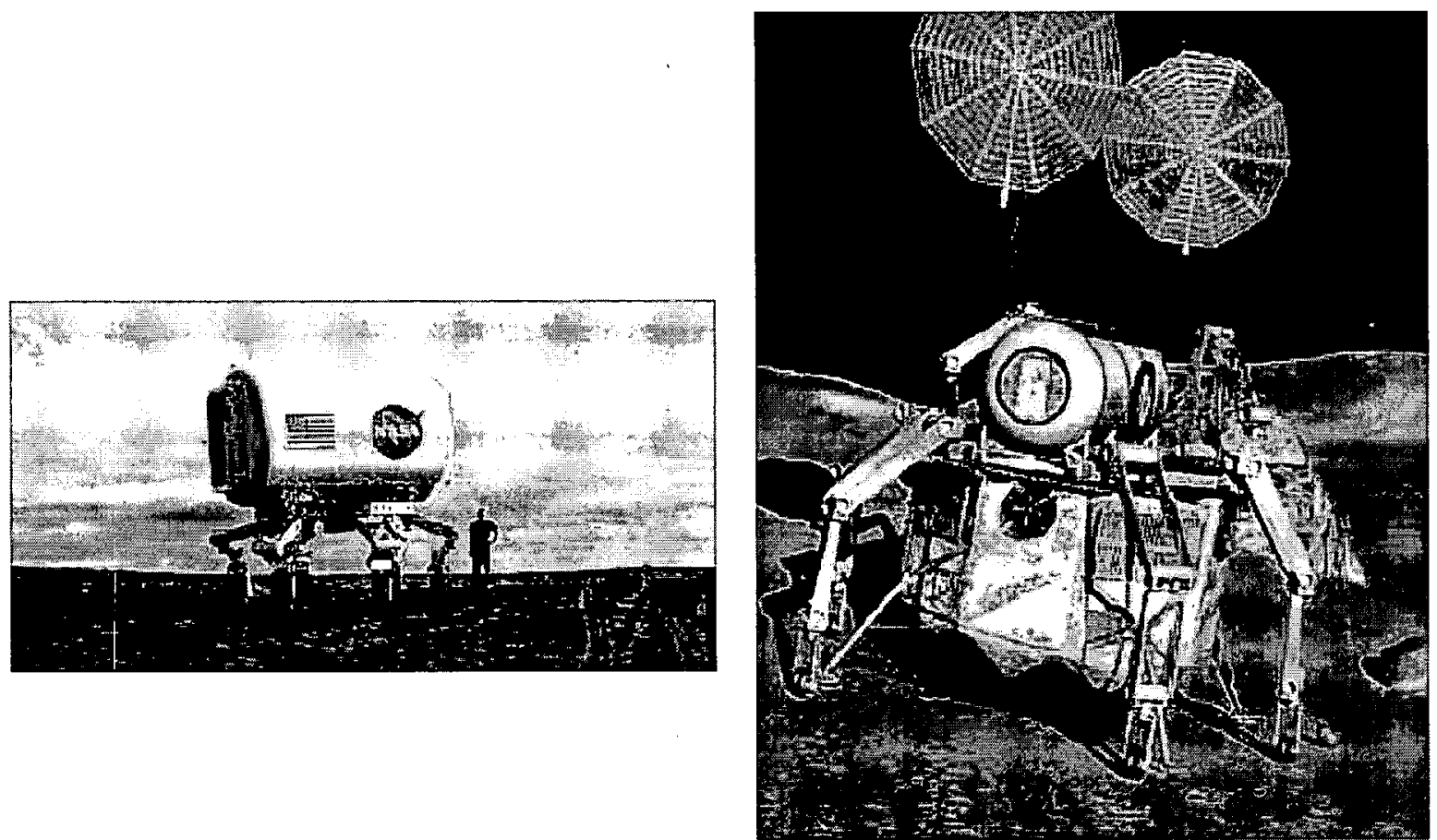

Figure 15. ATHLETE in a field test carrying Pressurized Module Mock-Up and a Lunar Concept Graphic Unloading a Cargo Lander. 


\section{Sortie Mission Chassis (SMC, Apollo Lunar Roving Vehicle Class)}

The Sortie Mission Chassis is a lightweight, four-wheeled rover similar to Lunar Roving Vehicle designed for sortie missions. It seats two crew members and can carry up to $490 \mathrm{~kg}$. (Culbert, 2009)

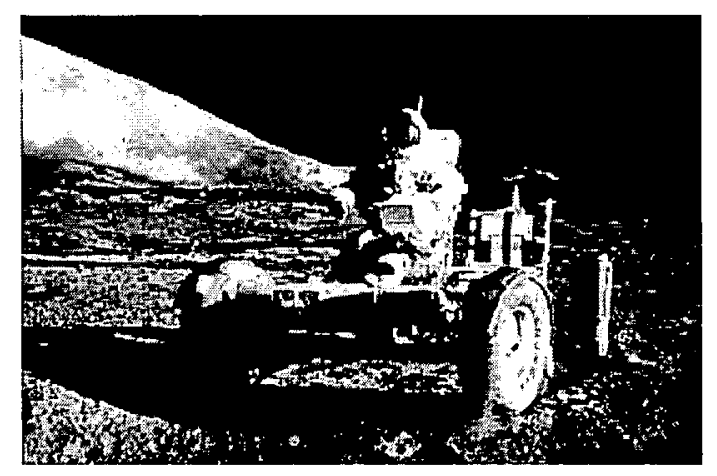

Figure 16. Sortie Mission Chassis - similar to Apollo LRV

Specifications:

$-210 \mathrm{~kg}$ vehicle mass

$.490 \mathrm{~kg}$ payload

-50 km max range

$\cdot 10 \mathrm{kph}$ max speed

-35 $5^{\circ}$ slope capability (payload dependent)

- $10 \mathrm{kWh}$ onboard energy storage (Li-ion battery)

-Driven onboard or remotely supervised

\section{Chassis A}

The Chassis A is a small four-wheeled vehicle designed to carry the Robot Assistant, a small version of an ISRU implement, or a sensor package. The chassis provides a workbench area for the robot assistant and a mount for tools, rock samples, or instruments. (Culbert, 2009) 


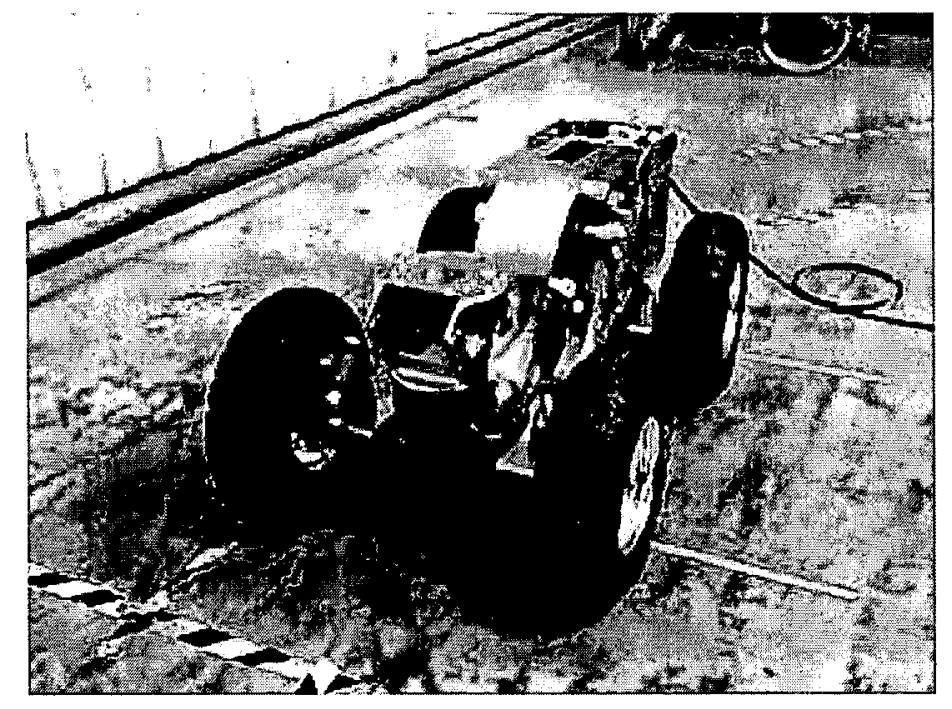

Figure 17. Chassis A - Small Mobility Platform Concept

Chassis Specifications:

$108 \mathrm{~kg}$ vehicle mass

$\cdot 100 \mathrm{~kg}$ payload

- $195 \mathrm{~km}$ max range

$\cdot 10 \mathrm{kph}$ max speed

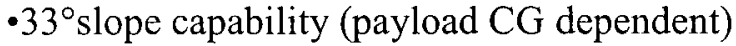

- $5 \mathrm{kWh}$ onboard energy storage (Li-ion battery)

-Driven remotely supervised

\section{Power \& Support Unit (PSU) \& Structural Support Unit (SSU)}

The PSU provides a support structure and launch interface for cargo elements, and it carries the RFC power system that provides solar power generation and $720 \mathrm{kWh}$ of energy storage for the outpost. Also carries an avionics and communications package to support outpost, a holding tank for scavenging water from landers, and provides structure to mount Habitat ECLSS and logistics resupply tanks. The composite structure works with a pressurized module or as a stand-alone unit, and can be configured without a power system as necessary (referred to as Structural Support Unit). (Culbert, 2009). 


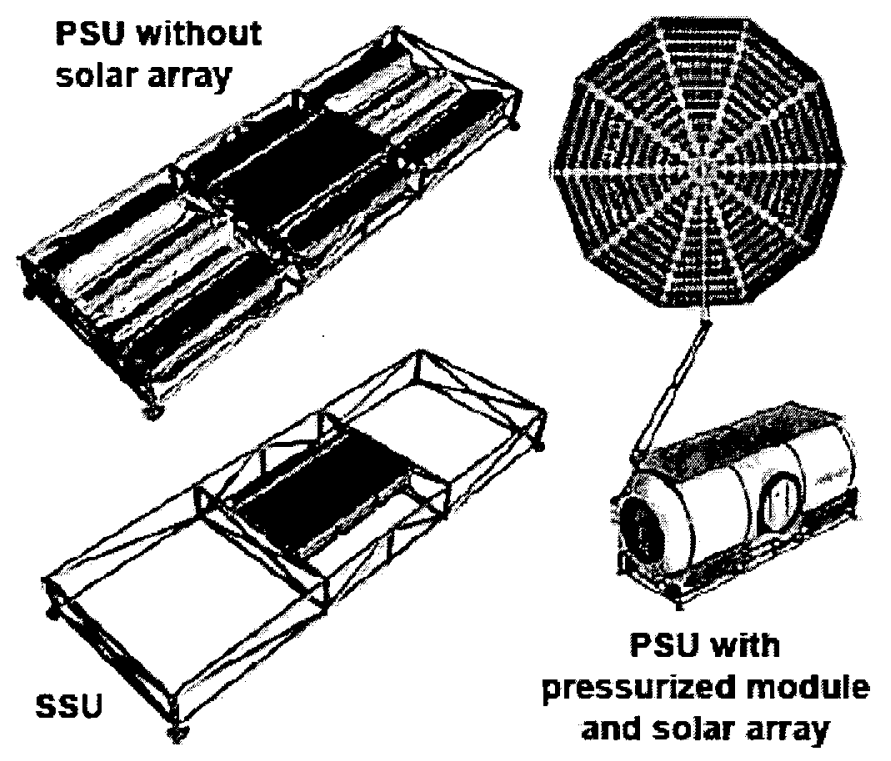

Figure 18. PSU and SSU Concepts

Specifications

-Mass: PSU 2,867 kg / SSU $680 \mathrm{~kg}$

-Energy storage

- 720 kWh Regenerative Fuel Cells

- Power generation

-9 meter array based on Orion design

-11.2 kW net solar array power

- Power consumables storage

-337 kg oxygen, $43 \mathrm{~kg}$ hydrogen; $450 \mathrm{~kg}$ water $\mathrm{x} 2$ (power and scavenge)

\section{Portable Utility Pallet (PUP)}

The PUP is a small logistics pallet with a solar array and batteries that provides a mobile power and consumables source for excursions in an LER. The PUP can also provide lander keep-alive power and water scavenging services. The PUP is designed to interface with the CMC during delivery to the lunar surface and on surface excursions. The PUP can also be transported on the surface using ATHLETE. Each PUP can carry the additional gas and liquid consumables to extend excursions to 14 days for 2 crew (LER nominally provides 3 days). (Culbert, 2009) 


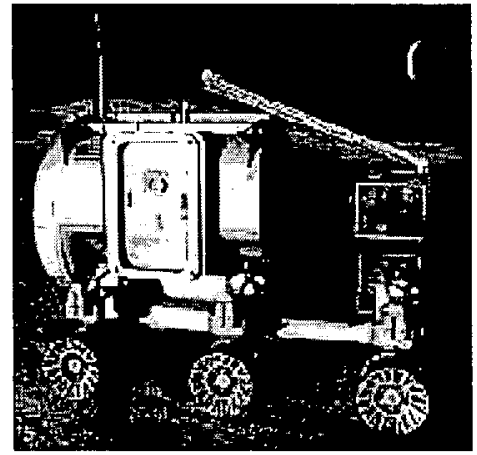

PUP stowed on LER

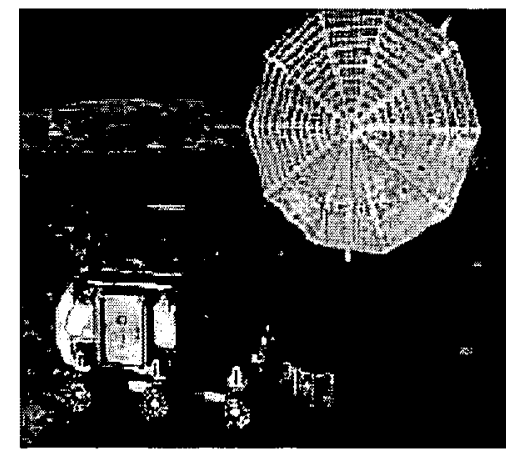

PUP deployed

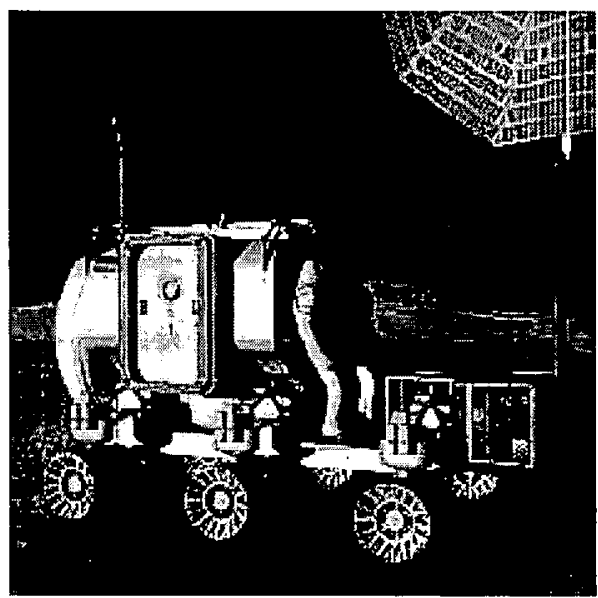

PUP attached to LER for use during excursion

Figure 19. PUP Configurations for Logistics

Specifications:

-Oxygen Capacity $=25 \mathrm{~kg}$

-Water Capacity $=90 \mathrm{~kg}$

-Wastewater Capacity $=90 \mathrm{~kg}$

-Power Generation: $4.385 \mathrm{~kW}$

-5.5 m diameter Orion-class solar array

-Energy Storage: $10 \mathrm{kWh}$ (Li-ion batteries)

-Mass

Mass:

Wet: $963.4 \mathrm{~kg}$

-Dry: $708.9 \mathrm{~kg}$ 


\section{Buried Fission Surface Power System}

Provide a single, centralized power source that can deliver continuous power for at least 8 years. Power management and distribution is provided by the Electrical Load Interface (ELI) located at the outpost. Shielding is enhanced by burying the FSPS in $2.3 \mathrm{~m}$ of regolith.

(Culbert, 2009)

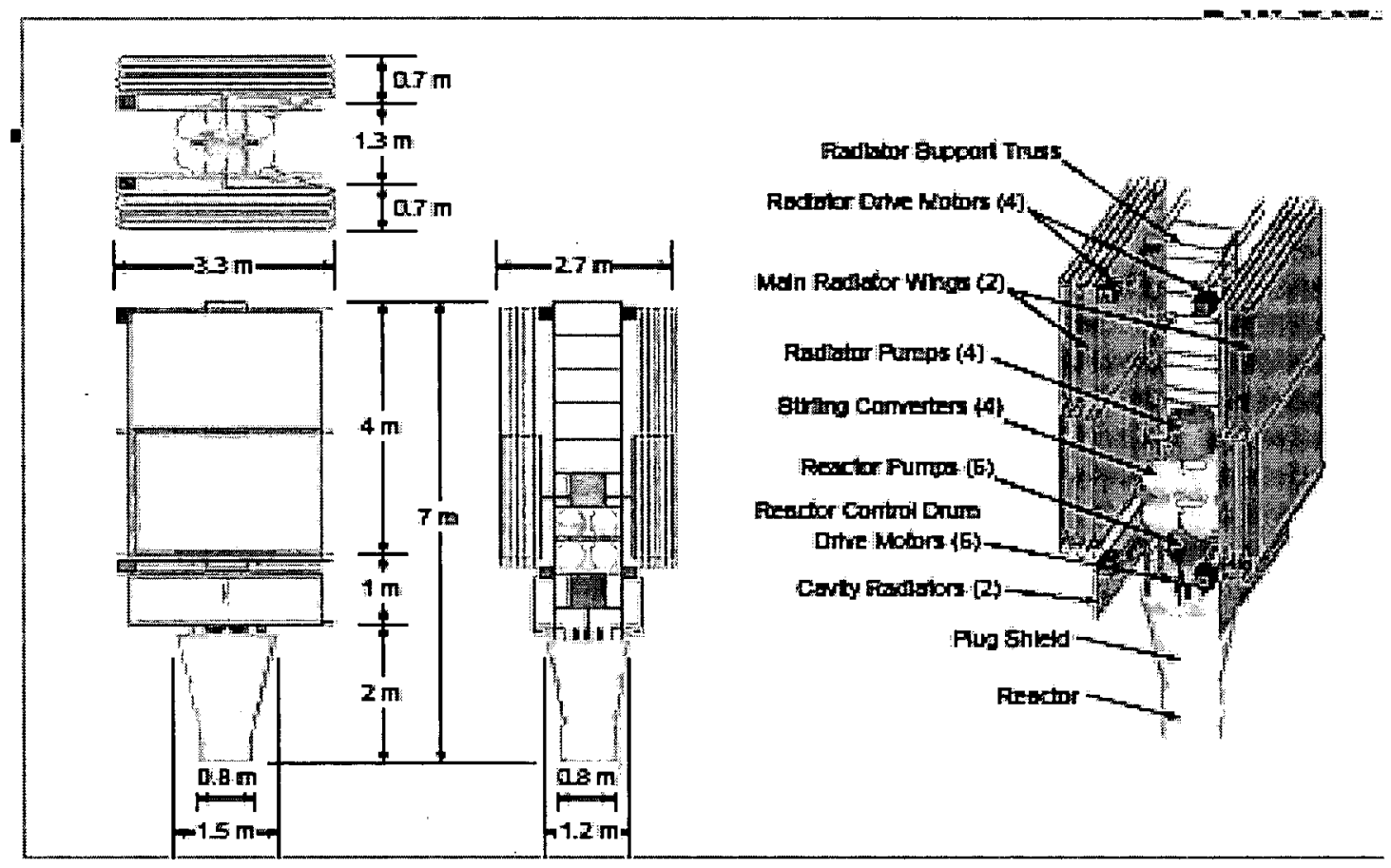

Figure 20. Fission Surface Power System (FSPS)

Specifications:

- Net Power Generated $=40 \mathrm{~kW}$ (daylight or eclipse)

-Total Mass $=6,902 \mathrm{~kg}$

(includes shield, PMAD, cables)

-Distance for $3 \mathrm{mrem} / \mathrm{hr}$ dose to unshielded astronaut $=100 \mathrm{~m}$

-Burial in Regolith augments delivered B4C shield 


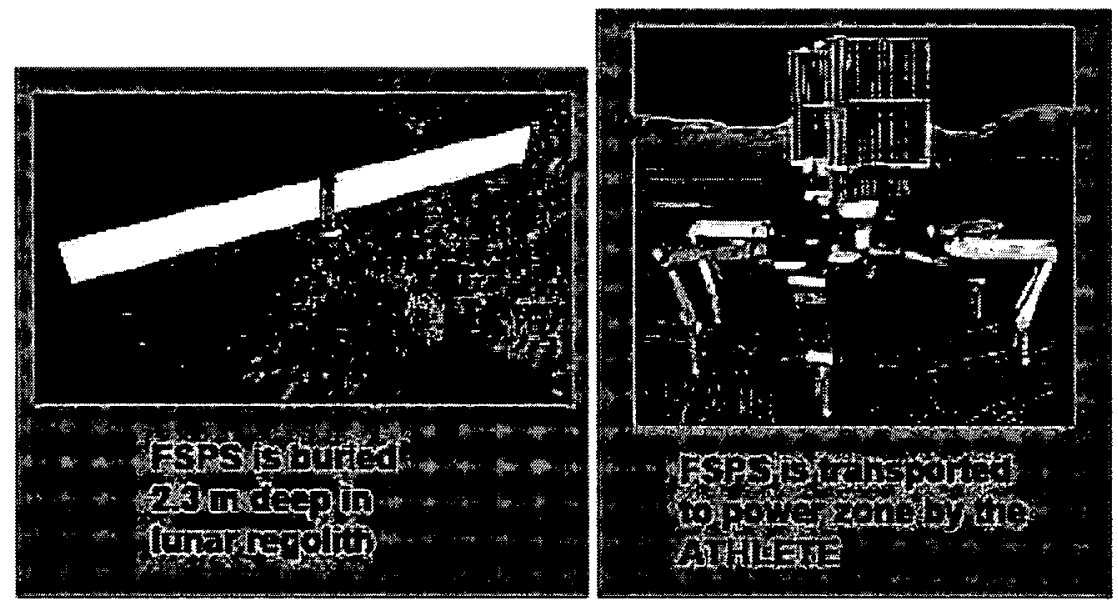

Figure 21. FSPS Buried in Lunar Regolith for Shielding Purposes.

\section{Robotic Assistant (RA):}

The Robotic Assistant has a two-jointed waist, allowing the arms to bend down to reach the ground, as well as swivel around and work with items on the chassis. The hands are fivefingered and dexterous, eliminating the need for specially designed gripping interfaces. The RA has a common interface enabling it to mount to any vehicle chassis or ATHLETE.

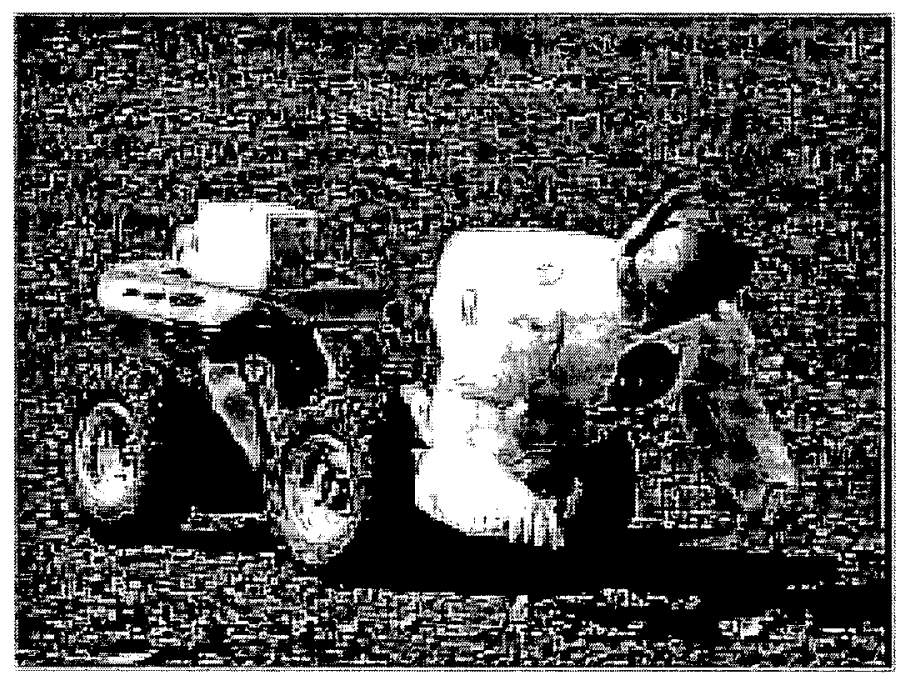

Figure 22. Robotic Assistant (RA) Concept Prototype

Specifications:

-Mass: $108 \mathrm{~kg}$ 
-Arm Strength: $\sim 50 \mathrm{~kg}(1 / 6 \mathrm{~g})$ at full extension

-Finger Strength: $\sim 12 \mathrm{~kg}(1 / 6 \mathrm{~g})$

-Waist Rotation: $-360^{\circ}$ to $360^{\circ}$

-Waist Tilt: $-60^{\circ}$ to $90^{\circ}$

-Neck Rotation: $-360^{\circ}$ to $360^{\circ}$

-Neck Tilt: $-60^{\circ}$ to $60^{\circ}$

\section{Lunar Surface Manipulator System (LSMS):}

The LSMS provides 6 metric ton lift capability at full reach to offload payloads from lander deck and manipulate payloads on the lunar surface. The LSMS can mount to the lander deck, vehicle chassis, or on the lunar surface, and can move between them unaided. Interchangeable end effectors facilitate a variety of capabilities such as forklift-like operations, inspections, site preparation, and regolith handling. (Culbert, 2009)

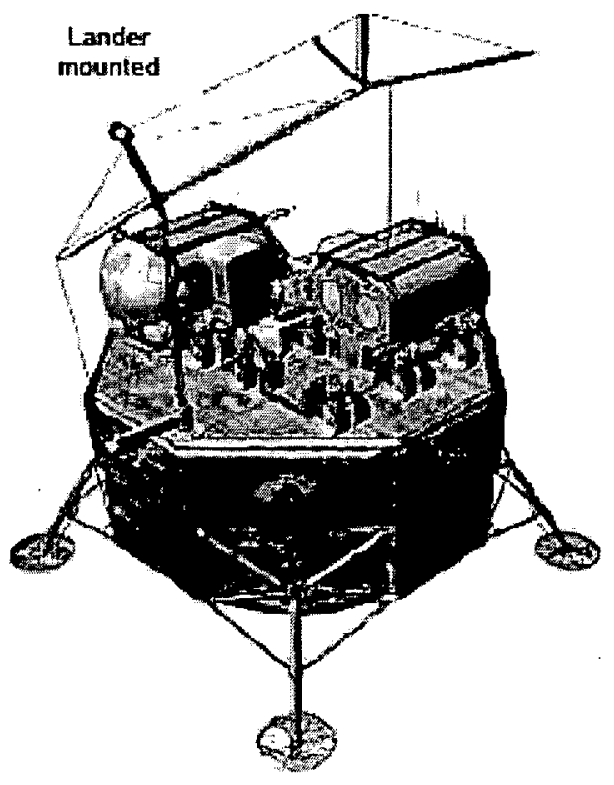

Figure 23. Lander Mounted LSMS Crane 

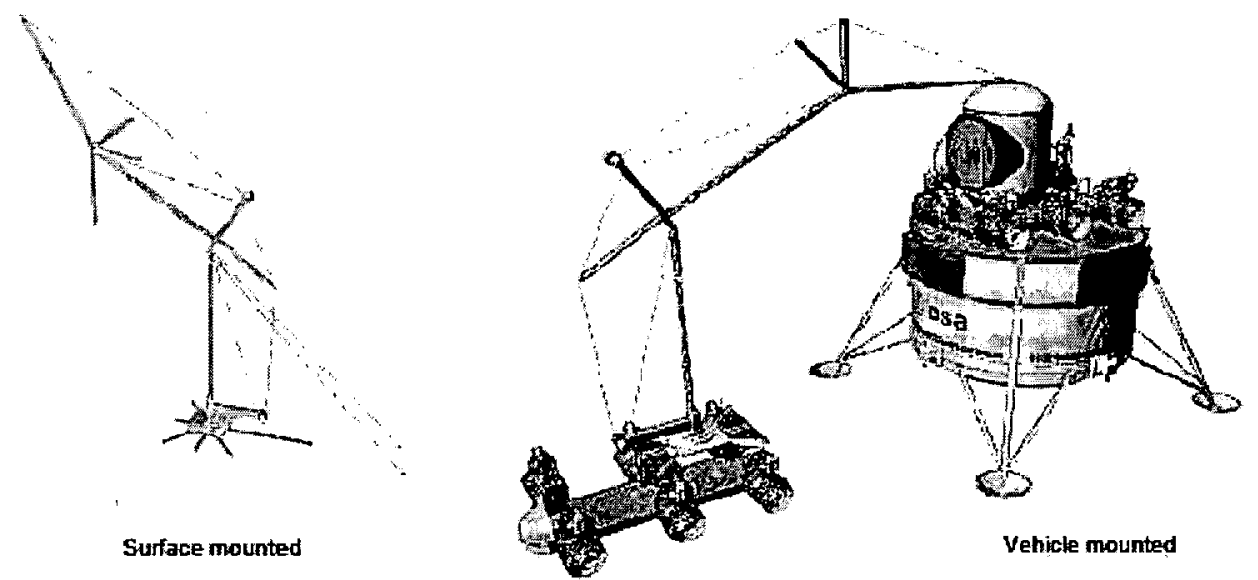

Figure 24. LSMS in Various Configurations

\section{Specifications:}

Mass: $190 \mathrm{~kg}$

Lift capability at wrist: $6 \mathrm{t}$

Lift capability at elbow: $10.4 \mathrm{t}$

Kingpost height: $3.75 \mathrm{~m}$

Reach: $7 \mathrm{~m}$

\section{Lunar Communications Terminal (LCT)}

The LCT provides a communication hub for the lunar surface. The services of LCT are gateway services (low and high data rates) data delivery to Earth via Lunar Relay Satellite (LRS) (primary) or via Direct to Earth (DTE) (secondary); surface wireless services; hardwire communication; data storage; local time; and routing.

Specifications:

-80 Mbps WLAN for lunar surface, $5.8 \mathrm{~km}$ range

-200 Mbps Ka band Return Link (26 GHz) to LRS or Earth

- $100 \mathrm{Mbps} \mathrm{Ka}$ band Forward Link $(23 \mathrm{GHz})$ from LRS or Earth

-3 Mbps S-band Return Link (2.2 GHz) to LRS or Earth; 24 kbps safe mode

-3 Mbps S-Band Forward Link (2.0 GHz) from LRS or Earth; 24 kbps safe mode

-150 Mbps bi-directional fiber connection

-Mass: $417 \mathrm{~kg}$

-Power required: $421 \mathrm{~W}$ (Nominal) 


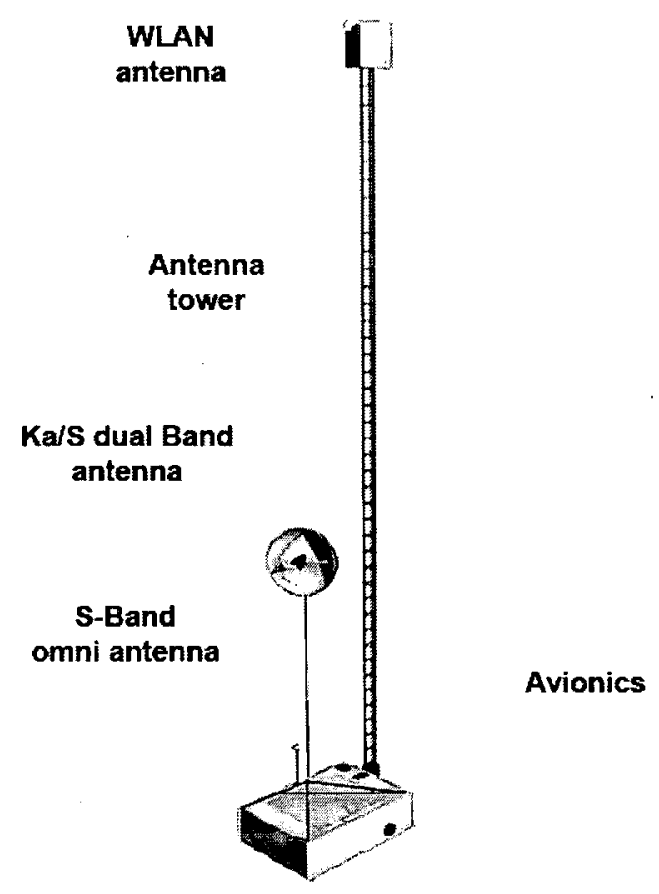

Figure 25. Lunar Communications Terminal (LCT) Concept

\section{ISRU Oxygen Production System (OPS)}

Perform lunar regolith excavation and handling, oxygen extraction from regolith, and oxygen storage and delivery. Supports lander propellant scavenging and water production. For flexibility, two 1/2-scale Oxygen Production Systems (OPSs) will be delivered and 2 sets of excavation tools.

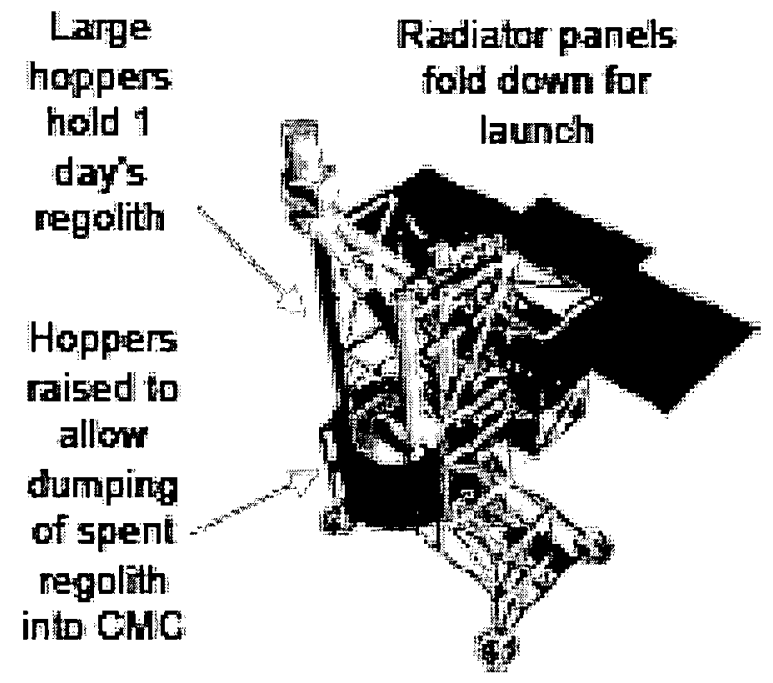

Figure 26. ISRU Oxygen Production Plant Concept 
Specifications:

- Total O2produced per plant $=500 \mathrm{~kg} / \mathrm{yr}$ (solar) \& $600 \mathrm{~kg} / \mathrm{yr}$ (nuclear)

- Mass per O2plant $=219 \mathrm{~kg}$

- Power required per plant $=3.93 \mathrm{~kW}$

- Total regolith per plant $=208 \mathrm{~kg} /$ day

-Excavation tools $=42.7 \mathrm{~kg}$ (each)

-Excavation time $=<1 \mathrm{hr} /$ day

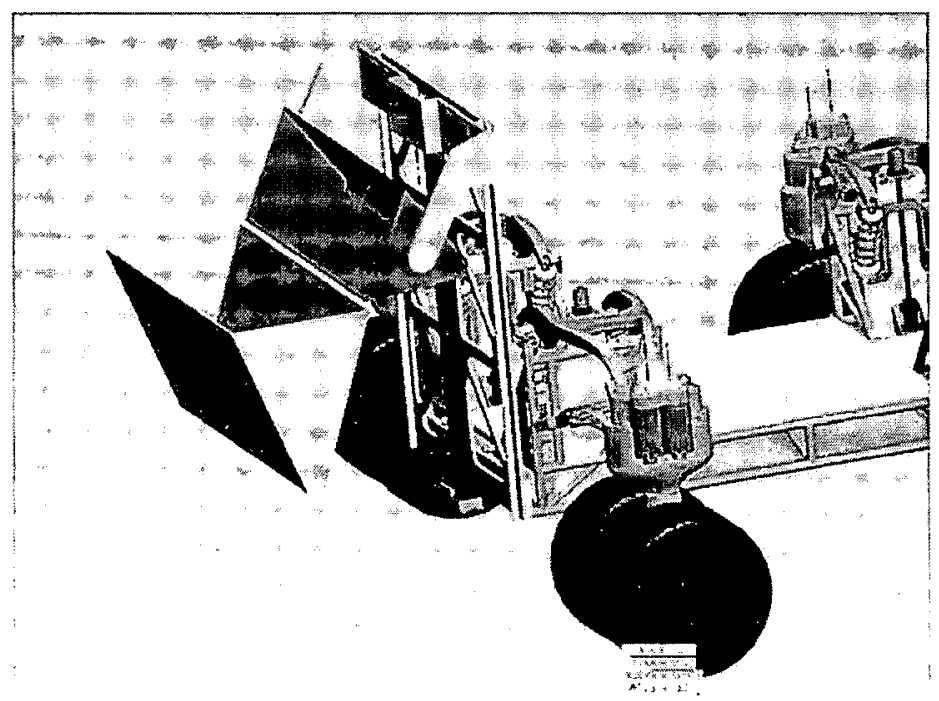

Figure 27. Front End Loader Regolith Excavator Concept for O2 Feedstock Mining

\section{COMPARISON OF A LUNAR EQUIVALENT SOUTH POLE CARGO TRAVERSE}

Although there are many differences between a Lunar scenario, and an Antarctic re-supply traverse, the elements used in each mission can be compared to get an estimation of the efficiency of the technologies involved. Therefore, in the following case study, the lunar outpost, (and associated equipment) have been ignored and selected lunar assets have been used to simulate an Antarctic traverse from McMurdo Base (equivalent to the Lunar Outpost) and the South Pole Station (Equivalent to a Lunar point of interest remote from the Lunar Outpost). This scenario and combination of elements has the additional benefit of being able to do Science research from the LERs and increased safety through the use of Robotic Assistants to scout the traverse route and measure it for crevasse danger while collecting scientific data en route. 
In order to deliver $384,589 \mathrm{~kg}$ of cargo over a South Pole equivalent traverse of $1,600 \mathrm{~km}$, in $1 / 6^{\text {th }}$ Gravity, then $66,862 \mathrm{~kg}$ of lunar support equipment (SE) would be required producing a Payload to SE ratio of 0.17 ; i.e. $1 \mathrm{~kg}$ of cargo delivered would require $0.17 \mathrm{~kg}$ of SE or about $1 / 6^{\text {th }}$ of the Cargo amount.

Table 5. Notional Support Equipment Ratios using Lunar Surface Systems Technology Estimates

\begin{tabular}{|r|r|r|r|r|}
\hline \multicolumn{1}{l|}{ Lunar Case } & Unit Mass (Kg) & \#Units & $\begin{array}{l}\text { Unit Payload } \\
\text { Capability (Kg) }\end{array}$ & \multicolumn{1}{l|}{ Total Mass } \\
\hline Lunar Electric Rover & 2,952 & 2 & & 2,952 \\
\hline CMC & 969 & 2 & & 1,938 \\
\hline PUP & 963 & 2 & & 1,926 \\
\hline Robotic Assistant & 108 & 2 & & 216 \\
\hline ATHLETE & 2,256 & 27 & 14,500 & 59,830 \\
\hline & & & & \\
\hline Lunar Support Equipment & 66,862 & & & \\
\hline Payload Mass & 384,549 & & & \\
\hline Total Mass & & & & \\
\hline & 451,411 & & & \\
\hline Support Equipment Ratio & & & & \\
\hline
\end{tabular}

\begin{tabular}{|r|r|r|r|r|}
\hline \multicolumn{1}{|l|}{ Antarctic Equivalent Case } & Unit Mass $(\mathrm{Kg})$ & \#Units & $\begin{array}{l}\text { Unit Payload } \\
\text { Capability }(\mathrm{Kg})\end{array}$ & \multicolumn{1}{l|}{ Total Mass } \\
\hline Lunar Electric Rover & 3,690 & 2 & & 7,380 \\
\hline CMC & 1,211 & 2 & & 3,423 \\
\hline PUP & 1,926 & 2 & & 432 \\
\hline Robotic Assistant & 216 & 2 & & 358,983 \\
\hline ATHLETE & 2,256 & 159 & 2,417 & \\
\hline & & & & \\
\hline Lunar Support Equipment & 373,069 & & & \\
\hline Payload Mass & 384,549 & & & \\
\hline & & & & \\
\hline Total Mass & 757,618 & & & \\
\hline & & & & \\
\hline Support Equipment Ratio & 0.97 & & & \\
\hline
\end{tabular}

If the same scenario is used and the equipment is adjusted for the Earth's Gravity, then $373,069 \mathrm{Kg}$ of SE would be required to deliver $384,589 \mathrm{Kg}$ of Cargo from McMurdo to the South Pole. This produces a Payload to SE ratio of 0.97 .

The information provided above by RPSC indicates that during an Antarctic Traverse in a 2009 re-supply mission to the South Pole from McMurdo, a Payload to SE ratio of 1.25 was achieved. 
This data, albeit highly simplified and notional, indicates that there is room for improvement in Antarctic re-supply traverse support equipment efficiencies. One way of doing this is to use lunar human-robotic systems technologies to achieve higher mass efficiencies and cost savings through reduced personnel in the field by using automation and remote supervised autonomy. The assumptions used indicate a large number of ATHLETE transporters (159 Units), but this may be reduced by further study and appropriate operational practices and applied robotic and structural design. These traverses could use lunar like equipment and technologies which would provide test data to the space program in a dual use and benefit mode of Antarctic cargo delivery.

\section{MARS SCENARIO PRELIMINARY ASSESSMENT}

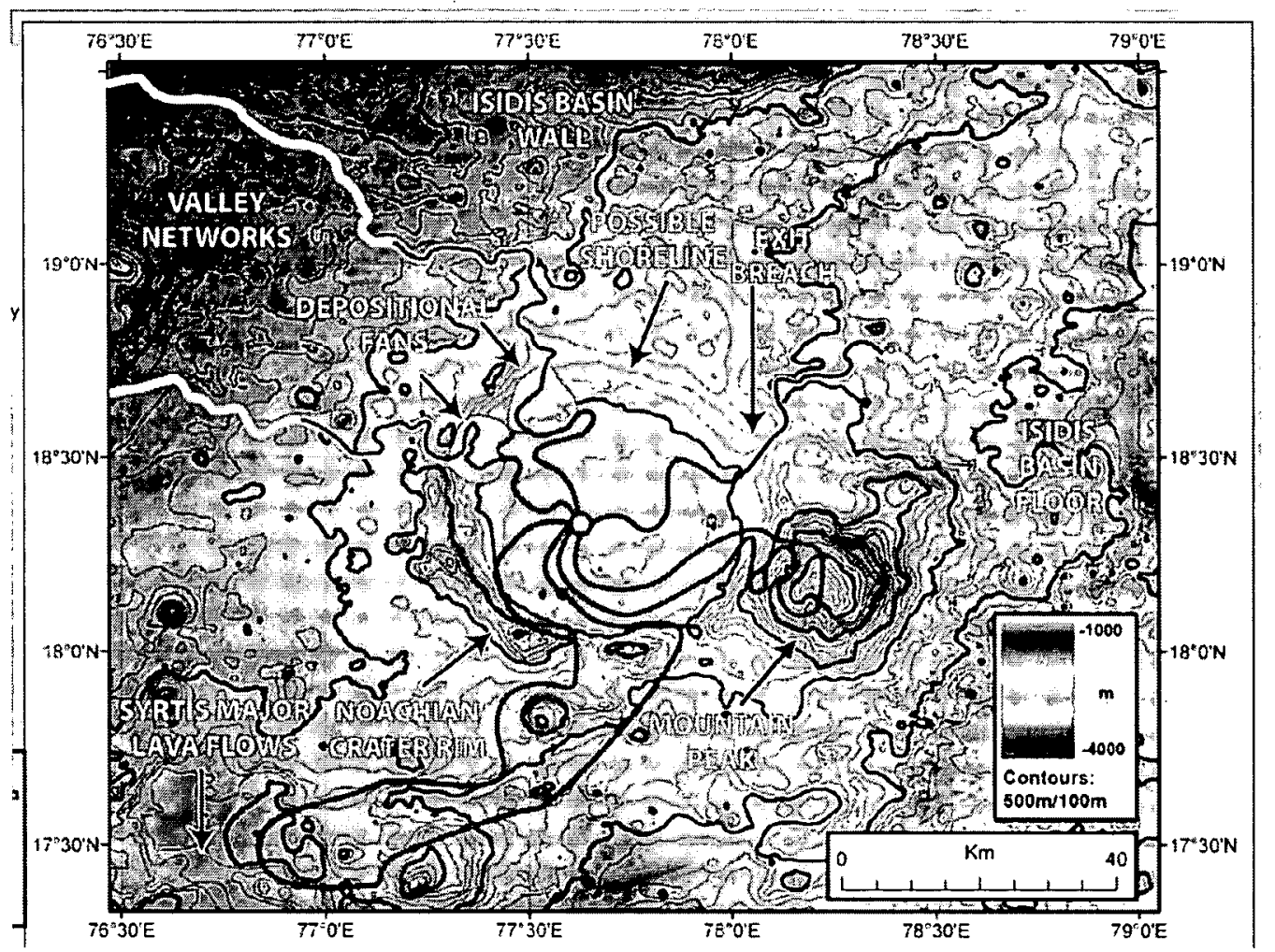

Figure 28. Notional traverses in the region located near the junction of the Isidis Planatia and Syrtis Major. (NASA image from Drake 2009a. Used with permission)

The most recent assessment of future traverses to be used for human exploration of the Martian surface was published in 2009 (Drake, 2009a and 2009b). Figure 28 illustrates one possible landing site on Mars and possible traverses that could be conducted from a central landing site. This figure shows that the scale of traverses envisioned for this landing site are measured in 100's of kilometer (although this is site dependent; a different site could have more compact traverse objectives or more distant objectives). Several different approaches for this activity were considered but no final decision has been made regarding a preferred 
approach. This is due in part to a relatively poor understanding within the NASA community about the implications of choosing one of these options over any of the others.

To illustrate the depth to which the current analysis of a Mars surface mission has been carried, the following table summarizes the categories and associated mass for one mission of six astronauts (Drake, 2009b).

Table 6. Mars Surface Mission, NASA Design Reference Architecture 5.0 showing Mass Categories and Estimates for a Habitat Lander and a Descent/Ascent Vehicle Lander.

\begin{tabular}{|c|c|c|c|}
\hline & & Hab Lander & DAV Lander \\
\hline Manifested Item & Quantity & CBE Mass (kg) & CBE Mass (kg) \\
\hline Crow Concumablac & & 15001 & \\
\hline Crew Consumables & & 1500 & 4500 \\
\hline Science & & 0 & 1000 \\
\hline Robotic Rovers & 2 & 0 & 500 \\
\hline Drill & 1 & 0 & 1000 \\
\hline Unpressurized Rover & 2 & 500 & 0 \\
\hline Pressurized Rover & 2 & 8000 & $\underline{0}$ \\
\hline Pressurized Rover spares & & (included above) & 0 \\
\hline Pressurized Rover growth & & 1600 & 0 \\
\hline Pressurized Rover power & 2 & 0 & 1000 \\
\hline Traverse Cache & & 0 & 1000 \\
\hline $\begin{array}{r}\text { Habitat } \\
\end{array}$ & 1 & 16500 & 0 \\
\hline Hab growth & & 5000 & 0 \\
\hline Hab spares & & (included above) & 0 \\
\hline Stationary Power System & 2 & 7300 & 7300 \\
\hline ISRU Plant & 1 & 0 & 1305 \\
\hline Ascent stage 1 (no LOX) & & 0 & 12156 \\
\hline Ascent stage 2 (no LOX) & & 0 & 9330 \\
\hline 30-day temp hab & & 0 & 0 \\
\hline Descent Stage (wet) & & 23300 & 23300 \\
\hline & & & \\
\hline Aeroshell & & 43700 & 43700 \\
\hline Total IMLEO Mass & & 107400 & 106100 \\
\hline
\end{tabular}

Gathering additional data and lessons learned from relevant sources, such as the U.S. Antarctic Program, will be a key element in making the ultimate decision on the type of surface exploration approach to use for human crews on Mars. The kinds of data that would be helpful in making these decisions include:

- Operational approach used to conduct a traverse, with supporting rationale 
- Numbers of personnel included on the traverse

- The skill mix among those people on the traverse

- The heated volume used (as a rough equivalent to pressurized volume for planetary missions)

- The amount of energy required to complete the entire traverse, broken down (roughly) between energy needed for mobility, life support, and other uses

- The mass of consumables and spare parts used to support the traverse

- The mass of payload devoted to the traverse objective (e.g., scientific instruments)

To support gathering actual operational data from similar exploration activities on Earth, a workshop was recently held at the NASA Johnson Space Center to discuss the parallels between human space exploration and polar exploration on Earth as well as lessons that have been learned on Earth that should be considered for these future missions (Hoffman and Cameron, 2010). Additional workshops of this type are envisioned to continue this dialog and exchange information in more detail.

\section{CONCLUSIONS}

Current work by professionals in the NASA space program and the NSF Antarctic program has been summarized with observations pertaining to the cross-utilization of methods, techniques and technologies. Of particular interest is the amount of support equipment required in order to deliver cargo on a traverse to a remote location in an extreme environment (such as Antarctica or the Moon), hundreds to thousands of kilometers away from a base where the cargo is staged. The simplified analysis in this study indicates that there is potential to improve the Antarctic program support equipment/cargo ratio by using NASA lunar surface system technologies while simultaneously providing a means of testing lunar surface systems element equipment in an extreme, remote environment.

Further work remains to be done and this study is notional and intended to gauge the potential for collaboration between NSF and NASA. Preliminary results indicate that collaboration is warranted for the mutual benefit of both organizations and improved traverse cargo delivery efficiencies may result in cost and schedule savings both in Antarctica and during future lunar missions.

\section{REFERENCES}

Culbert, Chris (2009). "Lunar Surface Systems Project Overview." NASA, http://www.nasa.gov/exploration/library/lss_systems concepts workshop.html.

Drake, Bret G., July 2009a, Human Exploration of Mars, Design Reference Architecture 5.0, NASA/SP-2009-566, Washington, DC: National Aeronautics and Space Administration.

Drake, Bret G., July 2009b, Human Exploration of Mars, Design Reference Architecture 5.0 
Addendum, NASA/SP-2009-566-ADD, Washington, DC: National Aeronautics and Space Administration.

Laurini, Kathy (2009). "International Partnerships and Interface Standards for Exploration." NASA, Exploration Systems Mission Directorate (ESMD), Directorate Integration Office, February 25, 2009, http://www.nasa.gov/pdf/315840main International Partnerships and Interfac e_Standards_for_Exploration_final_Laurini.pdf

Hoffman, Stephen J, and Andrew O. Cameron. 2010. Arctic and Antarctic Analogs for Planetary Surface Traverses. Paper presented at Earth and Space 2010 conference of the American Society of Civil Engineers, March 14-17, in Honolulu, Hawaii.

Hoffman, Stephen J. et al, NASA - Proceedings of the USAP Antarctic Traverse Workshop held in August 2009 at the Lunar Planetary Institute, Houston, Texas.

Hoffman, Stephen J. Ph.D., editor. NASA/TP-2002-210778, Antarctic Exploration Parallels for Future Human Planetary Exploration: A Workshop Report, April 2002

Stuster, J. (1996), Bold Endeavors: Lessons from Polar and Space Exploration.

Annapolis, MA: Naval Institute Press, 1996. 